\title{
AUSTRONESIAN SIBLING TERMS AND CULTURE HISTORY
}

\author{
ROBERT BLUST
}

\section{INTRODUCTION 1}

Proto Malayo-Polynesian (PMP), the hypothetical ancestor of all non-Formosan Austronesian languages, had four sibling terms: (1) *betaw, (2) *ñaRa, (3) *kaka/aka, and (4) *huaji. The first two terms referred to female and male cross-siblings respectively. The last two referred to elder and younger siblings, possibly only those of the same sex. In addition, there is widespread evidence of historically secondary morphemes meaning 'female/male' or 'female/male child' which replaced the original cross-sibling terms in many languages independently (the 'cross-sibling substitution drifts'). The unambiguous presence of a cross/parallel distinction in the sibling terminology is culturally significant, as it correlates statistically in synchronic data samples with the presence of descent groups, and in particular with matrilineal descent. The 'cross-sibling substitution drifts' have even greater cultural significance, as they are enigmatic unless we assume that PMP speakers practised some form of asymmetric exchange which persisted in many of its descendant communities until the terms for wife-giving and wife-taking groups had been transferred to the male and female cross-siblings respectively. Asymmetric systems of marital alliance survived into the ethnographic present primarily in Sumatra and eastern Indonesia, but were transformed in various ways in virtually all other Austronesian-speaking societies. More generally, in the area of general ethnological method and theory this paper takes issue with several widelyshared assumptions about necessary and sufficient conditions for historical reconstruction, and describes the first reported instance of a linguistic drift that is powered not by structural pressures in the linguistic system, but rather by structural pressures in the system of social organisation.

\subsection{THE PROBLEM}

Although language families such as Indo-European and Sino-Tibetan have more speakers, Austronesian (along with Niger-Kordofanian) is one of the world's two largest language families in number of languages (Ruhlen 1987). ${ }^{2}$ These languages have a wide geographical distribution in Taiwan, the Philippines, Malaysia, Indonesia, portions of mainland Southeast Asia, Madagascar and a variety of Pacific nations located within the broad geographical

1 I am indebted to Alice Dewey, Gregory Forth, Rodney Needham and Andrew Pawley for critical comments which led to improvements in an earlier version of this paper. Needless to say, none of these scholars necessarily accepts my premises, methods, arguments or conclusions.

2 Ruhlen (1987) recognises 1,064 Niger-Kordofanian and 959 Austronesian languages. Needless to say, these numbers are meaningful only to the extent that a common definition of 'language' and 'dialect' is uniformly applied.

A.K. Pawley and M.D. Ross, eds Austronesian terminologies: continuity and change, 31-72. 
regions of Melanesia, Micronesia and Polynesia. As with any large and widely distributed collection of languages or cultures, there is a great deal of linguistic and cultural diversity among the Austronesian-speaking peoples. Since they reflect a common ancestral tradition the differences among these various languages and cultures must have arisen through an accumulation of gradual linguistic and cultural changes over many generations. It is the task of the comparative linguist to reconstruct as much as can be recovered of the language which existed before these changes. Because language and culture are interconnected in sometimes surprising and unexpected ways, the reconstruction of particular linguistic features may, under favourable circumstances, also entail the reconstruction of interconnected features of culture.

Somewhat over a decade ago on the basis of comparative linguistic evidence I argued that early Austronesian (AN) society had ancestor-oriented kin groups (descent groups), matrilateral cross-cousin marriage (hereafter simply 'matrilateral cousin marriage'), dual divisions and some kind of quadripartite social organisation (Blust 1980b). This point of view was contrary to one expressed in Murdock (1949), but agreed closely with certain features of the reconstruction of "ancient Indonesian" social organisation proposed in 1935 by the Dutch ethnologist F.A.E. van Wouden in a thesis written under the supervision of J.P.B. de Josselin de Jong. ${ }^{3}$

The anthropological debate into which I as a linguist to some extent unwittingly thrust myself is of greater than ordinary interest for at least three reasons. Firstly, Murdock's ideas on early Austronesian social organisation were one of many spin-offs from his worldwide study of the typology of kinship systems. Even in 1980, over 30 years after they were first expressed, his historical reconstructions of social organisation and change for particular language families remained perhaps better grounded in general ethnological theory than those undertaken by any other contemporary anthropologist. Secondly, the close similarity of my inferences from the linguistic evidence with many (not all) of those expressed by van Wouden was arrived at quite independently, and at a time when the pioneering work of this Dutch scholar was being vigorously re-examined both for its importance and for its shortcomings (Fox, ed. 1980). Thirdly, this disagreement over the narrow details of early Austronesian social organisation can be seen as a test of the larger issue whether ethnology has a comparative method of the same order of reliability as the comparative method of historical linguistics. Indeed, with reference to his "technique of historical reconstruction" Murdock (1949:349) believed that "the most striking confirmation of the method comes from the Malayo-Polynesian stock".

The evidence that I cited in support of my position in 1980 was of varying value, but central to my line of reasoning (especially as expressed in my Reply) was the history of sibling terminology in Austronesian languages. It was my position then, and it remains my position today that through a comparative analysis of sibling terms alone - without reference to the broader matrix of reconstructed kinship terminology - one can safely reach two

The expression 'early Austronesian' served as a convenient cover term, since the actual reconstructions varied between two non-contemporaneous protolanguages, Proto Austronesian and Proto MalayoPolynesian, both of which were explicitly indicated in relation to any given protoform. The same convention, with the same provision, is used in this paper. With regard to the expression "ancient Indonesian", van Wouden (1968[1935]:86) himself refers to "exclusive cross-cousin marriage and its organisational correlate" as "an ancient culture-element known to all the peoples in the area". Although he evidently intended this statement to apply only to eastern Indonesia, de Josselin de Jong (1977[1935]:168) called the same features of social organisation "the structural core of numerous ancient Indonesian cultures in many parts of the Archipelago". 
conclusions: (1) that speakers of a language ancestral to all non-Formosan Austronesian languages had descent groups, and (2) that within the same language community there was a rule of matrilateral cousin marriage, or on the level of the corporate kin group, what LéviStrauss (1969[1949]) has called "generalized exchange" (more commonly known today as 'asymmetric alliance'). ${ }^{4}$

The first of these claims is relatively non-controversial, assuming only that the correlations between type of sibling terminology and type of social structure which Murdock (1968) found to be statistically significant in attested societies should also hold in reconstructed prehistoric societies. ${ }^{5}$ Being founded on a statistical, rather than a logical argument, its validity is essentially probabilistic. The second, more iconoclastic claim, has emerged from a synthesis of comparative linguistics and elements of kinship theory that is more abstract, and perhaps more difficult to follow. Unlike the first it is founded on a logical argument, and its validity therefore depends on the usual criteria of compatibility with the primary data, and competitive superiority (based on simplicity and independent motivation) which govern the evaluation of inductive arguments in science generally.

To forestall possible misunderstanding at the outset, I wish to emphasise that my inference of PMP asymmetric alliance is based not on an assumed correlation between reconstructed terminology and behaviour, but rather on an assumed correlation between semantic change and behaviour. I will distinguish these types of relationship between language and behaviour as 'horizontal' and 'vertical'. The first approach (followed, for example, by Murdock, and used here only for my claim of PMP descent groups) is essentially a projection of relationships in a synchronic system onto a reconstructed language. The second approach, which is an essential part of the practice of historical linguistics, has a potential for the solution of diachronic problems in social and cultural anthropology which has never been fully appreciated and has rarely been exploited by anthropologists. Its use is illustrated in, for example, Blust (1986-87) and (1987a).

This paper is devoted to a broad comparative treatment of Austronesian sibling terms, with special reference to what I call 'the cross-sibling substitution drifts'. The problem is complex, and requires the resources both of comparative historical linguistics and of the anthropological study of kinship. For this reason I do not have the luxury of assuming a

4 James J. Fox (pers.comm.) has taken issue with my use of the expressions descent group and corporate kin group as interchangeable labels. After some consideration of his objections I fail to see any basis for them (one might quibble similarly with my interchange of 'structure' and 'organisation'). The distinction that I wish to make separates systems of social organisation in which kin group membership is defined by lateral extension from systems of social organisation in which it is defined by common descent from an apical ancestor. It is customary in the anthropological literature to refer to kin groups of the latter type as descent groups, and because they persist through time despite changes in their membership they are corporate. Ego-centered bilateral kin groups such as Murdock's bilateral kindred cannot be corporate, since their composition varies with each person in relation to whom they are defined. Further distinctions which may be important to the ethnographer (e.g. corporate kin group vs localised corporate kin group) probably are beyond the means of the comparative method of linguistics to reconstruct, but a reconstruction that is less refined than the ethnographer would like is not therefore to be dismissed as worthless.

5 One might, of course, object that the statistical correlations presented by Murdock are themselves suspect, a criticism that has been raised in particular by British scholars (e.g. Leach 1961). However, the objections to Murdock's methods that have been raised to date fail to explain how a compounding of largely random errors could produce consistent patterns of correlation cross-culturally. Like Nerlove and Romney (1967) I take the results of Murdock (1968) as given. While these results themselves may be controversial, the uniformitarian view that statistically significant correlations which hold in modern cultures also held in prehistoric cultures has been to date almost completely free from dissent. 
shared intellectual background, as is normally the case when one writes for others in one's own academic discipline. Serious gaps in communication between anthropologists as a group and linguists as a group were painfully obvious in at least one recent attempt by an anthropologist to apply comparative techniques to the reconstruction of kinship systems (Marshall 1984), and I hope by supplying the necessary background to avoid such problems here.

\section{ANTHROPOLOGICAL PREREQUISITES}

Although some important contributions were made by earlier scholars, it is perhaps fair to say that the anthropological study of kinship received its major initial impetus from the publication of Lewis Henry Morgan's 'Systems of consanguinity and affinity of the human family' (1870). In this work and in his sequel, Ancient society (revealingly subtitled Researches in the lines of human progress from savagery through barbarism to civilization), Morgan was concerned with developing sociological explanations for the differences between types of terminological systems. Morgan saw a fundamental difference between what he called "classificatory" systems, which he associated with less advanced societies, and "descriptive" systems, which he associated with more advanced (viz. European) societies. Morgan's general evolutionary schema, his arbitrary distinction between classificatory and descriptive systems, and many of his sociological explanations for the composition of kin groups now appear fanciful, but his belief that it is possible to correlate types of terminological systems with underlying social and economic determinants has been shared by subsequent anthropologists, who have developed it in increasingly sophisticated forms.

Kinship theory has taken enormous strides since Morgan's pioneering work, and it would be a daunting task to review even the major contributions here. I touch only briefly on a few points that are particularly relevant to the argument that follows.

\subsection{TERMINOLOGY}

Kinship relations are commonly expressed by a set of abbreviations which isolate a single, universally definable category in relation to a given individual, designated as Ego. Such universally-defined kin categories are the primitives of kinship theory, since they are independent of the kinship categories of any particular language. When combined to form language-particular configurations which are mapped onto a single morpheme they become genealogical categories, that is, culturally-defined categories of relationship. In the ensuing discussion expressions such as 'both cross-cousin' will refer to primary universal categories unless there is specific indication to the contrary (thus one is justified in speaking of 'both cross-cousins' in symmetric alliance even though there may be a single culturally-recognised category which covers both universal categories). The abbreviations used in this paper for universally-defined kin categories are as follows: 


$\begin{array}{ll}\mathrm{F}=\text { father } & \mathrm{M}=\text { mother } \\ \mathrm{B}=\text { brother } & \mathrm{Z}=\text { sister } \\ \mathrm{S}=\text { son } & \mathrm{D}=\text { daughter } \\ \mathrm{H}=\text { husband } & \mathrm{W}=\text { wife } \\ \mathrm{m}=\text { male } & \mathrm{f}=\text { female } \\ \mathrm{m} . \mathrm{s} .=\text { man speaking } & \text { w.s. = woman speaking } \\ / /=\text { same sex (parallel) } & \mathrm{x}=\text { opposite sex (cross) } \\ \mathrm{e}=\text { elder } & \mathrm{y}=\text { younger } \\ \mathrm{Sb}=\text { sibling } & \end{array}$

Other kin categories are represented by combinations of these elementary terms: $\mathrm{MBD}=$ mother's brother's daughter, FZS = father's sister's son, $\mathrm{eSb}=$ elder sibling, $\mathrm{xSb}=$ sibling of the opposite sex, etc.

Some other distinctions that will be useful in this paper are:

consanguines: persons related by culturally recognised common descent;

affines: persons related by marriage;

lineal kin: kin related in a direct line, as grandparents, parents and children;

collateral kin: all consanguines other than lineal kin, as uncles and aunts, siblings, cousins, nephews and nieces;

descent group: a group of kin defined in relation to a common ancestor - such groups are corporate in the usual sociological sense, that is, they maintain their identity through time despite changes in individual membership;

lineage: the most commonly recognised form of descent group (often a lower-order descent group whose members can trace the links and line of common ancestry, as opposed to the 'clan', where they cannot);

exogamy: a prescribed rule of marriage outside Ego's descent group (marriage within the descent group is culturally-defined incest, whether with a close biological relative or not);

cross-cousin marriage: a culturally expressed preference for a male Ego to marry a woman who belongs to the kin category MBD or FZD. This takes three forms: patrilateral cousin marriage (with FZD), matrilateral cousin marriage (with $\mathrm{MBD}$ ) and bilateral cousin marriage (with either cross-cousin);

unilineal descent: culturally recognised descent exclusively through one parental line;

patrilineal descent: culturally recognised descent exclusively through the father's line, which may produce patrilineal lineages, or patrilineages;

matrilineal descent: culturally recognised descent exclusively through the mother's line, which may produce matrilineal lineages, or matrilineages;

ambilineal descent: culturally recognised descent through either a patrilineage or a matrilineage, dependent upon particular socioeconomic circumstances;

bilateral descent: culturally recognised descent through both parental lines. This is also known as cognatic descent.

As noted by Robin Fox (1967:169) some confusion has arisen in the anthropological literature through use of the terms 'bilateral' or 'cognatic' to cover two radically different 
types of descent reckoning. Firstly, the term has been applied to collections of kin defined in relation to a particular Ego (or better, sibling set). Murdock (1949) calls this type of kin group a bilateral kindred. Since individuals do not live indef initely long, bilateral kindreds cannot persist through time; indeed, at any given point in time the membership of a bilateral kindred is the same only for siblings. It is thus impossible for a bilateral kindred to form descent groups.

Secondly, the term has been applied to collections of kin defined in relation to a common ancestor. Fox (1967:172) calls this type of kin group an unrestricted cognatic lineage. Unlike the bilateral kindred the unrestricted cognatic lineage does include descent groups. In Fox's words, "what matters is not so much the division into unilineal and cognatic, as the difference between the ego-focus on the one hand with its personal 'groups', and the ancestor-focus on the other with its descent groups". We will take up this distinction again in section 2.3.1.

\subsection{COUSIN TERMS, SIBLING TERMS AND SOCIAL STRUCTURE}

Beginning with Kroeber (1909) it has been common practice in kinship theory to analyse systems of terminology into their operative features (much like the use of distinctive features in phonology). Kroeber identified eight such features as operative in kinship systems generally. Murdock (1949:100ff.) reduced these to six by conflating three features which Kroeber distinguished (sex of relative, sex of connecting relative, sex of speaker) to the single feature 'sex'. Sex of relative requires little explanation, as it is productively employed in English for all relatives except cousins (father : mother; uncle : aunt; brother : sister; son : daughter; nephew : niece, etc.). Sex of connecting relative is inoperative in English, but is needed for those terminological systems that distinguish parallel cousins (children of father's brother or mother's sister) from cross-cousins (children of father's sister or mother's brother). Sex of speaker is similarly inoperative in English, but is needed (among other reasons) for those systems that distinguish parallel siblings (brother of a man, sister of a woman) from cross-siblings (brother of a woman, sister of a man).

Based primarily on the way in which cross-cousins are classified it has been common at least since Spier (1925) to assign whole terminological systems to a general typological schema. Basing himself solely on North American Indian data, Spier recognised eight general types of kinship system; Murdock (1949:224), drawing on a global sample, recognised eleven, together with various subtypes. For our present purposes the most important types and their definitions, following Murdock (1949:223ff.) are: (1) HAWAIIAN: all cross and parallel cousins are called by the same terms as those used for siblings; (2) OMAHA: FZD and MBD are called by different terms and terminologically differentiated from sisters and parallel cousins, but FZD is terminologically classed with ZD and/or MBD with MZ; and (3) CROW: FZD and MBD are called by different terms and terminolgically differentiated from sisters and parallel cousins, but FZD is terminologically classed with FZ and/or MBD with BD. In short, Hawaiian systems of cousin classification include only relatives of Ego's generation, but do not distinguish lineal from collateral relatives. By contrast, Omaha and Crow systems distinguish lineal from collateral, but group the cross-cousins with kin of adjacent generations (the patrilateral female cross-cousin with $\mathrm{ZD}$ in Omaha, but with $\mathrm{FZ}$ in Crow; the matrilateral female cross-cousin with $\mathrm{MZ}$ in Omaha, but with BD in Crow). 
For most of the twentieth century cousin terminology has formed the basis of kinship typologies, and has provided the clearest evidence of statistically significant cross-cultural correlations between kinship terminology and other features of social organisation. Over seventy years ago Lowie (1917:151ff.) drew attention to the seemingly non-accidental correlation between Omaha systems of cousin terminology and patrilineal descent on the one hand, and between Crow systems of cousin terminology and matrilineal descent on the other. This finding was confirmed and placed within a larger explanatory context by Murdock (1949). 6

Much more recently, with the appearance of Nerlove and Romney (1967) and Murdock (1968), there has been an emerging awareness that systems of sibling terminology can profitably be arranged in general typological schemas much like systems of cousin terminology, and that statistically significant cross-cultural correlations can be found between the resultant types and other features of social organisation.

Based on a sample of 800 societies from all parts of the world, Murdock (1968) isolated seven types of sibling terminologies, defined by him as follows (number of instances in Murdock's sample appears in parentheses): TYPE A: The Kordofanian or Undifferentiated Sibling Type. The prevailing pattern is a single term, which may be glossed as 'sibling' (69); TYPE B : The Yoruba or Relative Age Type. The prevailing pattern is a pair of terms, which may be glossed as 'elder sibling' and 'younger sibling' (86); TYPE C : The Algonkian or Skewed Age Type. The prevailing pattern consists of three terms, which may be glossed as 'elder brother', 'elder sister' and 'younger sibling' (74); TYPE D : The Dravidian or AgeSex Type. The prevailing pattern has four terms, which may be glossed as 'elder brother', 'elder sister', 'younger brother' and 'younger sister' (177); TYPE E : The European or Brother-Sister Type. The prevailing pattern has two terms, which may be glossed as 'brother' and 'sister' (156); TYPE F : The Melanesian or Relative Sex Type. Defined by primary distinctions of relative sex, which may assume one of four essentially alternative forms: (1) two terms, which may be glossed as 'sibling of the same sex as Ego' and 'sibling of the opposite sex' (80); (2) three terms, glossed as 'sibling of the same sex', 'brother (woman speaking)' and 'sister (man speaking)' (63); (3) three terms, glossed as 'sibling of opposite sex', 'brother (man speaking)' and 'sister (woman speaking)' (32); and (4) four terms, glossed as 'brother (man speaking)', 'brother (woman speaking)', 'sister (man speaking)' and 'sister (woman speaking)' (26); TYPE G : The Siouan or Complexly Differentiated Type. Defined by the application of all three distinctions - relative age, sex and

6 Typologies based on criteria other than cousin terminology were developed by Lowie (1928) and Kirchhoff (1932), but have been less widely used in the global characterisation of kinship systems. Needham (1962b, 1974:50-61, pers.comm.) denies the validity of Murdock's correlations on the grounds that the categories compared are artificial, and of little value in determining basic similarities and differences of social structure. Specifically, he argues that Murdock's coupling of descent principle and type of cousin terminology to define eleven basic types of social structure for all human societies ignores the more fundamental and far-reaching structural consequences of differences in marriage rule and number of descent lines. In this respect he is firmly in the Structuralist tradition of Lévi-Strauss (1969[1949]), and I am in complete sympathy with his views. However, these criticisms have no bearing on the present argument, which does not depend in any way on the acceptance of Murdock's eleven types of social structure, or even on the acceptance of such widely acknowledged terminological categories as 'Crow', 'Omaha', 'Iroquois', 'Hawaiian' and the like. To affect the present argument Needham's criticism would have to demonstrate that the notions 'descent group' and 'relative sex' are ill-def ined, and of no utility to cross-cultural studies. Even if he should succeed in this, the criticism would affect only my argument for PMP descent groups, not my argument for PMP asymmetric exchange, which is supported by evidence of an entirely different kind. 
relative sex - to such an extent as to prevent recognition of any possibly more basic pattern (37).

Perhaps the most important contribution of Murdock's paper is its attempt to establish what he calls "functional determinants" of terminological patterns. For the first of these determinants Murdock examines the correlation of rule of descent with type of sibling terminology, and reaches the following conclusions: (1) ambilineal descent appears especially conducive to the emergence of sibling terms of Type F; (2) bilateral descent appears relatively conducive to Types $\mathrm{B}, \mathrm{D}$ and $\mathrm{G}$, and reveals a negative association with Types A and F; (3) matrilineal and double descent appear especially conducive to Type F; (4) patrilineal descent appears particularly conducive to Type E; and (5) except for differences in Types $\mathrm{E}$ and $\mathrm{F}$, matrilineal and patrilineal societies show an almost identical profile, contrasting at almost every point with the profile of bilateral societies. For the second determinant he examines the correlation of type of sibling terminology with type of cousin terminology, and concludes (p.14) that "the types of the two subsets vary almost completely independently".

\subsection{PAST VIEWS OF EARLY AUSTRONESIAN SOCIAL STRUCTURE}

Over the past seven decades a number of anthropologists have attempted to reconstruct the major outlines of early Austronesian social structure, and have reached very different conclusions. The lines of division between these conclusions are perhaps most clearly drawn with regard to two sets of questions: (1) Were descent groups present? (2) If cross-cousin marriage was practiced was it symmetric (both cross-cousins), or asymmetric (only the matrilateral cross-cousin)?

\subsubsection{DESCENT GROUPS OR NOT?}

Kroeber (1919) compared the kinship terminology of various Philippine ethnic groups and reached the following conclusions about early Philippine society: (1) no distinct cousin terms could be reconstructed; (2) there were only two sibling terms, 'eSb' and 'ySb'; (3) descent was bilateral, with no lineages present; and (4) there was no form of preferential marriage.

Murdock (1949:349ff.) reached a similar conclusion for the Austronesian-speaking peoples as a whole, maintaining that "the original Malayo-Polynesian speaking community had a social organization of Hawaiian type". By this Murdock (p.228) means a society "possessing cousin terms of Hawaiian type and lacking exogamous unilinear kin groups. In addition, it is characterised by the exceedingly frequent appearance of limited polygyny, the bilocal extended family, generation terminology for aunts and nieces, bilateral extension of incest taboos, and bilateral kindreds or demes". Murdock's conclusions about Austronesian as a whole thus agree explicitly with Kroeber's conclusions about early Philippine society in regard to points (1), (3) and (4).

More recently James J. Fox (1988b) has reviewed Kroeber's arguments, and reached conclusions similar to those of both Kroeber and Murdock (although he considers only island Southeast Asia). In particular, Fox generalises Kroeber's point (3) to island Southeast Asia as a whole, and he argues (p.42) that "the regional development of lineal systems may 
have begun to develop in the southern Philippines and became more elaborated in the Indonesian islands, particularly in eastern Indonesia".

A strikingly different reconstruction of early Austronesian social organisation was proposed by the Dutch social anthropologist F.A.E. van Wouden in 1935. In it he used data for a number of societies in eastern Indonesia, drawn both from the domain of kinship and from the domain of mythology to posit an original system of "circulating connubium" or marital alliance between descent groups which was realised through matrilateral cousin marriage. Van Wouden's general structural model, which has been extensively criticised by subsequent scholars (Fox, ed. 1980), has many points of contact with that of Lévi-Strauss (1969[1949]).

To summarise, van Wouden claimed that a community ancestral to most of the societies of eastern Indonesia possessed descent groups (or lineages), and a system of political alliance founded on matrilateral cousin marriage, while at least Murdock (1949:349-350) and Fox (1988b) have denied that early Austronesian society had either of these features. What can linguistic comparison contribute to a resolution of this debate? Murdock (1968) has firmly established a statistically significant correlation between Type F sibling terminology ("defined by primary distinctions of relative sex") and lineal, particularly matrilineal, descent. Moreover, he notes (p.12) that "bilateral descent" is negatively associated with Type F terminology. Murdock (1967:49) distinguishes bilateral descent based on "Ego-oriented bilateral kin groups or categories" from bilateral descent "with reported or probable quasilineages", but in his 1968 paper he fails to indicate which type of bilateral descent he means. Even without further clarification regarding this point, however, it is clear that Type F sibling terminology has a statistically well-established cross-cultural association with the presence of descent groups. If it could be shown that a reconstructed language had Type $\mathrm{F}$ sibling terminology it would follow that speakers of that language probably traced descent through some form of lineage system, most likely through matrilineages.

\subsubsection{SYMMETRIC OR ASYMMETRIC ALLIANCE?}

Van Wouden's reconstruction of eastern Indonesian social organisation posited a system of "asymmetric connubium", by which he meant a culturally favoured or expected type of marriage between a man and his classificatory mother's brother's daughter. In his view (1968[1935]:87) matrilateral cross-cousin marriage was "not merely a popular form of marriage within a narrow circle of consanguineous kin, but...the logical expression of a systematic communication of women among larger social groups". A more general model of this type of social organisation (called "generalized exchange"), in which matrilateral crosscousin marriage is viewed as the foundation of sociopolitical alliances, was developed by Lévi-Strauss (1969[1949]), who observed that minimally such a system requires three exogamous groups (so that no group, A, is both wife-giver and wife-taker with another group, B). Although van Wouden explicitly recognised the same theoretical relations, he reconstructed a system of asymmetric alliance for the societies of eastern Indonesia in which not three, but rather four groups participate, and he further arranged these in a "double twophratry system" (p.92ff.).

Although it was first pointed out by J.P.B. de Josselin de Jong and van Wouden in 1935 , Needham (1962a, ed. 1973) in particular has demonstrated that systems of asymmetric alliance are not confined to the regulation of marriage, but tend to form total conceptual 
orders in which material, social and cosmological notions are encompassed under a unifying dualistic schema. Among the Purum, a Tibeto-Burman-speaking group of Manipur, eastern India, for example, this schema of dual symbolic classification includes, but is not confined to, the following categories:

TABLE 1: PURUM DUAL SYMBOLIC CLASSIFICATION (after Needham 1962a)

$\begin{array}{ll}\text { Left } & \text { Right } \\ \text { Affines } & \text { Kin } \\ \text { Wife-takers } & \text { Wife-givers } \\ \text { Inferior } & \text { Superior } \\ \text { Female } & \text { Male } \\ \text { Below } & \text { Above } \\ \text { Earth } & \text { Sky } \\ \text { Bad death } & \text { Good death } \\ \text { Profane } & \text { Sacred }\end{array}$

Strikingly similar systems of dual symbolic classification have been reported for a number of Austronesian-speaking societies in Indonesia, including the Toba Batak of Sumatra (Vergouwen 1964[1933]), the Atoni of Timor (Cunningham 1964; Schulte-Nordholt 1971:407ff.), the Tetun of Timor (Hicks 1976:44ff., 108), and the Kambera of eastern Sumba (Forth 1981:37-44). Indeed, the classic essay of Hertz (1973[1909]) suggests that there is a universal dualistic conceptual schema which differs only in particular details from one society to the next. Such schemas appear to be found in societies with a wide range of marriage systems, but when they co-occur with systems of matrilateral cousin marriage they assign wife-takers to the category that includes 'left' and 'female' and wife-givers to the category that includes 'right' and 'male'.

Despite van Wouden's strong emphasis on the 'original' character of asymmetric systems, not all of the societies of eastern Indonesia are asymmetric. As noted in the contributions edited by Fox (1980), although virtually all of the societies of eastern Indonesia practise some form of marital alliance between descent groups, there is an exuberant and sometimes perplexing variation in the form that such alliance systems take. Needham $(1967,1984)$ has argued, contrary to van Wouden, that the original form of social organisation in eastern Indonesia was based not on asymmetric alliance, but rather on symmetric alliance. ${ }^{7}$ Aberle (1980) and Barnes (pers.comm.) suggest much the same, and Forth (1990) has explicitly argued for an evolution from symmetry to asymmetry within a more restricted region of eastern Indonesia. On the level of the individual symmetric alliance is realised through bilateral cross-cousin marriage (marriage with either classificatory cross-cousin), and in such an arrangement both exchange groups are equally wife-giver and wife-taker. The question of group hierarchy as determined by an established and deliberately perpetuated direction of marital alliance - a characteristic which is so prominent in asymmetric systems (see Table 1) - thus cannot arise in the symmetric variant.

How can linguistic evidence help to determine whether systems of symmetric or of asymmetric alliance have an older history in the Austronesian language family? The matter here is not so simple as determining whether or not descent groups were present, and before

7 Neetham further distinguishes between 'prescriptive' and non-prescriptive terminologies. More precisely, then, he has argued for an evolution of attested terminological systems from an earlier terminological system of symmetric prescriptive alliance. I disregard the issue of prescriptive vs non-prescriptive terminology in constructing my argument, as it appears to have no bearing on the outcome. 
it can be approached meaningfully some background in comparative linguistics is essential for the non-linguist reader.

\section{LINGUISTIC PREREQUISITES}

Between about 1890 and the time of his death in 1913, the Swiss linguist Ferdinand de Saussure laid the foundations for the study of language as part of a general theory of signs. Central to a number of his analyses was the principle of the "arbitrariness of the linguistic sign", or the generally non-iconic relationship between sound and meaning. It is this principle which makes it possible to determine whether similarities between languages have a value as markers of shared history, or whether such similarities might as easily be attributed to the independent operation of language-universal tendencies. Ironically, the field of historical linguistics, which may be said to owe its existence to Saussure's insight, actually developed long before this insight had been explicitly formulated.

\subsection{THE COMPARATIVE METHOD OF LINGUISTICS}

The comparative method of linguistics was developed in connection with the establishment of the Indo-European language family and the reconstruction of its hypothetical immediate common ancestor, Proto Indo-European. This undertaking occupied several generations of scholars, and today stands as one of the great intellectual achievements of the nineteenth century. Like the theory of evolution by natural selection the comparative method of lingaistics continues to provide a scientific paradigm within which productive research is conducted. Its fundamental soundness as a tool for prehistoric inference has been validated repeatedly over more than a century and a half, at first almost entirely through research on the Indo-European languages, but increasingly in this century through comparative research on a variety of other language families (for the classic extension of the method to non-western languages see Bloomfield $(1925,1928)$; for the proceedings of a recent symposium devoted to the universality of the comparative method see Baldi (1990)) ${ }^{8}$

One of the key discoveries made by Rask and Grimm during the first two decades of the nineteenth century and later refined by Grassmann, Verner and the Neogrammarians, is the regularity of sound change, of ten referred to as the 'Regularity Hypothesis'. It is the Regularity Hypothesis which makes it possible to distinguish linguistic similarity due to chance or borrowing from linguistic similarity due to divergent descent from a common ancestor, and hence to reconstruct earlier stages of linguistic (and cultural) history. Sound correspondences are exemplified in morphemes, and morphemes of similar meaning which exhibit recurrent sound correspondences are said to be cognate. ${ }^{9}$ Based on sets of cognate morphemes in at least two widely separated languages one reconstructs protophonemes, protoforms and ultimately protolanguages. It is a fundamental premise of historical linguistics that cognation is established on the basis of recurrent sound correspondences

8 About ten years ago, in discussing diachronic issues in ethnology with a distinguished European social anthropologist who specialises in Southeast Asia, I was asked (much to my astonishment) whether historical linguistics hadn't been 'discredited'. More than anything I can add, remarks such as these expose the gulf that has come to separate linguistics and anthropology in many universities during the past quarter of a century, much to the detriment of progress with diachronic issues in ethnology.

9 For reasons explained in Blust (forthcoming b) I prefer 'recurrent sound correspondence/recurrent sound change' to 'regular sound correspondence/regular sound change'. This deviation from the strict Neogrammarian position has no effect on the argument presented here. 
rather than on the basis of phonetic similarity. The two may, and often do coincide, but many phonetically similar morphemes in different languages are not cognate, and many cognate morphemes in different languages are not phonetically similar.

Regretfully, there have been several linguistic analyses in the anthropological literature relating to Indonesia in recent years which show that the concept of 'cognate' continues to be misunderstood by well-meaning social anthropologists who have an interest in historical issues in ethnology, but who lack training in the tools best suited to approach such issues. One of the major aims of this paper is therefore to demonstrate the central importance of adequate methods of historical reconstruction in linguistics to historical reconstruction in ethnology. 10

The successes of the comparative method of linguistics have so of ten been celebrated that its shortcomings are sometimes overlooked by those who rely on secondhand knowledge. One point that should be emphasised is that the reconstruction of a 5,000 or 6,000 year-old protolanguage is not a high resolution affair. Some social anthropologists rather naively expect the comparative linguist who is involved in reconstruction to be able to distinguish between theoretical models of social organisation that are of interest to kinship specialists working with attested societies. This type of expectation can be compared to a demand that astronomers using earth-based telescopes distinguish features a few metres in size on the surface of Mars. No protolanguage of any great time-depth, not even Proto Indo-European, has been reconstructed in such fine detail that we can, for example, translate a passage of more than a few words from a modern language into it (despite some overly-ambitious nineteenth-century attempts to do so).

One other matter than can be raised here concerns a belief expressed by Aberle (1980:226228), Fox (1980a:234, 1988b:36ff.) and Forth (1985:137, 1990:389) that (in the words of the last-mentioned writer) "terminological reconstructions should proceed from the bottom up, by comparing cognate terms from the smallest sub-groupings before positing prototerms for such inclusive groupings as PAN and PMP”. This point of view, unjustified as it is, is surprisingly widespread, not only among anthropologists, but even among some linguists (Blust 1976b:354). The reconstruction of Proto Indo-European did not proceed "from the bottom up", nor did, for example, Dempwolff (1934-38) see the need to reconstruct Proto Tagalic, Proto South-West Barito, Proto Malayic or Proto Polynesian before reconstructing

10 Particularly egregious examples are Forth $(1985,1990)$ and Fox $(1988 \mathrm{a})$. In the first of these papers it is argued that Kambera (Sumba) layia 'WB, ZH' (dubiously analysed into two morphemes la-yia) is a reflex of Proto Malayo-Polynesian *hipaR 'sibling-in-law (probably of the same sex only)'. Apart from the fact that the reconstruction is repeatedly written incorrectly as *ipay/hipay, Forth's entire argument is based on a priori notions of plausible cross-linguistic similarity rather than on a consideration of recurrent sound correspondences, which would have shown him that there is no precedent for his claim that PMP ${ }^{*} p$ disappeared in Kambera (the expected form of ${ }^{*} h i p a R$ in Kambera is $\left.{ }^{* *} i p a\right)$. In the second paper Forth (1990):376ff.) candidly acknowledges that his understanding of 'cognate' is a relationship based purely on phonetic similarity, and then proceeds to erect an elaborate historical argument based on the comparison of East Sumbanese mamu 'FZ, FZH' with reflexes of PMP *mama 'MB' despite an obvious irregularity in the sound correspondences (cf. PMP *ama $>$ KMB /ama ' $F$ ', *ina > /ina/ ' $M$ '. In the third paper Fox attempts to connect the arbitrarily segmented first syllable of PMP *puqun "base of a tree, foundation, origin' with the arbitrarily segmented last syllable of *empu 'grandparent/grandchild (reciprocal)', and both of these with *tumbuq 'to grow' through its Proto Oceanic form *tumpuq. This argument, presented by a highly accomplished ethnographer, shows so many serious misunderstandings of motphology, the Regularity Hypothesis and the interrelationships of protolanguages of different timedepths that one hardly knows where to begin the process of correction. Fortunately, we are far better off in the Oceanic branch of Austronesian, where prominent anthropologists such as Goodenough, Chowning and Green are well-trained in the basics of comparative linguistics. 
Proto Austronesian based on a direct comparison of such languages as Tagalog, Ngaju Dayak, Malay, Tongan or Samoan. In fact, the reconstruction of such lower-order protolanguages as Proto Germanic profited enormously from the prior existence of reconstructions for Proto Indo-European, as in the formulation of Verner's Law. Anttila (1972:346) calls the reconstruction of lower-order protolanguages through reference to external witnesses "inverted reconstruction", and Blust (1972c: Iff.) calls the same procedure "reconstruction from the top down". In both cases its value is emphasised. Moreover, as noted in Blust (1976b), the logical outcome of a strict inductivist approach to linguistic reconstruction such as that recommended by Forth as the only acceptable one, is a potentially infinite regress to the comparison of dialect, subdialect and even idiolect before any useful comparative work can commence.

Finally, it should be appreciated that all languages change over time. What this means to the practising comparative linguist is that situations may arise in which it is necessary to reconstruct some feature for a protolanguage which is retained unchanged in none of its descendants (though its distinctness from other features must be retained in at least two witnesses for it to be reconstructable). The justification for such reconstructions, as for any others, is always: (1) compatibility with the primary data for which an explanation is sought, and (2) competitive simplicity in relation to alternative hypotheses. Since all languages change, the raw material of comparative linguistics is that part of prehistoric languages involving an arbitrary association of sound and meaning which has survived in several widely separated descendants. The collection of languages which retain any given feature will differ from one linguistic feature to the next. If some feature of a prehistoric language is distinguished in only one descendant we will have no basis for reconstructing it, even though it was present in the language we wish to reconstruct. For this reason the description of a reconstructed language is inevitably less complete than that of an attested language. In conducting diachronic research on a language that existed five or six millenia in the past one learns to accept a certain measure of crudity in comparison with what could be accomplished if direct observation were possible. The same caveat applies to the reconstruction of cultures that are associated with such prehistoric languages: for a social anthropologist to demand that a linguistic reconstruction provide details that are descriptively important to anthropological theory may be unreasonable, given the general lability of both linguistic and cultural forms over a period of millenia. It is a remarkable fact that the comparative method allows us to penetrate confidently to a time-depth of perhaps six millenia, and any general feature of social organisation that can be inferred from such reconstructed language material is a gift that we are not likely to receive in any other way.

\subsection{SEMANTIC RECONSTRUCTION}

When historical linguists speak of linguistic reconstruction what is normally meant is the reconstruction of phonemes (phonological reconstruction) and morphemes (lexical reconstruction). It should be recognised that phonological and lexical reconstruction are interdependent processes, since phonemes can only be reconstructed on the basis of correspondences in cognate morphemes. Hence protophonemes and protomorphemes (or etyma) are reconstructed together. Methods and procedures for syntactic reconstruction (as distinct from the reconstruction of inflectional morphology) have generally lagged far behind those for phonology and the lexicon. 
In contrast to phonological/lexical reconstruction, where well-established methods have been available for generations, and to syntactic reconstruction, which until recently has been largely ignored due to the lack of adequate methods of historical inference, semantic reconstruction has occupied an awkward limbo somewhere in between. On the one hand, reconstructed morphemes must be assigned meanings. Unlike syntactic reconstruction, which is relatively independent of phonological/lexical reconstruction, the problem of semantic reconstruction cannot, therefore, simply be ignored. On the other hand, no generally accepted method exists for reconstructing meanings such as exists for the reconstruction of phonemes.

In many, perhaps most cases, this unfortunate state of affairs does not lead to serious problems. The comparison of Tagalog lajit, Malay lajit, Manggarai lajit, Kei lanit, Samoan laji, all meaning 'sky' requires no semantic inference apart from the relatively uncontroversial one that *lagit must have meant 'sky'. But what are we to do with cognate terms that differ in meaning, such as English thatch next to Dutch dak, German Dach 'roof (of any material)'? Here the forms compared exhibit recurrent phonological correspondences (for the initial consonant, compare, for example, three : drie : drei, or thief : dief: Dieb; for the final consonant, compare rich : rijk : Reich, or such : zulk : solch), but what did Proto West Germanic * $\theta a k$ mean?

Dyen and Aberle (1974) have developed a set of procedures for matching reconstructed morphemes with predetermined categories of meaning. They call this set of procedures "lexical reconstruction". It is essential to recognise that lexical reconstruction is interested only in the matching of reconstructed morphemes with meanings that are drawn from the lists of languages compared. In their approach no reconstructed morpheme can have a meaning which is not reflected unchanged in at least two languages that belong to different primary subgroups. They thus have no methodologically motivated basis for glossing a form such as Proto West Germanic * $\theta a k$, where one primary subgroup (represented by English) reflects the meaning 'thatch', while the other primary subgroup (represented by Dutch and German) reflects the meaning 'roof'.

Blust (1987a) contrasts lexical reconstruction as advocated by Dyen and Aberle with a fundamentally different approach, called "semantic reconstruction". Unlike lexical reconstruction, in which one asks the question 'What was the protomorpheme which probably meant ' $X$ '?', semantic reconstruction requires one to ask the very different question 'What was the probable meaning of protomorpheme ' $X$ '?'. The procedure of semantic reconstruction turns about two crucial concepts: (1) the meaning of a lexical item in an attested or a reconstructed language is determined by contrast within a field of lexical items of partially similar meaning, and (2) two reconstructed lexical items with radically different 'semantic profiles' must have differed in meaning. The first of these concepts is the familiar Saussurean approach to the determination of the structural units of language: "Language is a system of interdependent terms in which the value of each term results solely from the simultaneous presence of the others..." (Saussure 1966[1915]:114). The second concept ensures that we have some basis for explaining radically different trajectories of semantic evolution in the reflexes of protoforms that could be glossed the same using the Dyen-Aberle approach. 11

11 Oddly, Forth (1990:389, and fn. 20) attributes to me a belief that categories of meaning in reconstructed languages must be identical to categories of meaning in their descendants: "The case of tuya also illustrates the need to formulate particular courses of terminological change in advancing an evolutionary 
Before concluding this section one other methodological issue should be aired. Fox (1988b:36, pers.comm.) has insisted that any conclusions about social organisation which are based on reconstructed kinship terminology must await the reconstruction of a complete terminological system. This requirement is consistent with the Saussurean approach to meaning in general, and I am in full agreement with it as it applies to synchronic systems. However, Saussure (1966:90) clearly distinguishes between what he calls "the two linguistics" (static and evolutionary, or synchronic and diachronic), and he maintains (p.91) that "the synchronic and diachronic 'phenomenon'...have nothing in common...One is a relation between simultaneous elements, the other the substitution of one element for another in time, an event". It may be useful to think of these respectively as 'horizontal' and 'vertical' relations of meaning. Misunderstanding has arisen where Fox (and some other social anthropologists) have approached diachronic analyses as though they are simply synchronic analyses of past systems. What this approach overlooks is the dimension of change linking past synchronic systems with present synchronic systems, a dimension which is at least partially recoverable from a comparison of the glosses of heterosemantic cognate forms. The fact that English clock, a generic term for any stationary timepiece, is cognate with Dutch klok, German Glocke 'bell (and clock)' surely is not without significance for our understanding of the history of time-keeping in the European cultural tradition. Moreover, the reconciliation of these divergent glosses under a single etymon yields a valuable historical inference that can be justified outside any system of past or present synchronic contrasts. Rather than mechanically reconstructing a Proto West Germanic morpheme for 'clock' (based on an agreement of meaning in all three languages) we must infer not only a meaning 'bell', but also a behavioural precondition for the transfer of meaning, hence a cultural practice (dating at least from the Middle Ages) of using bells for the public marking of time. Similar arguments supporting an inference of earlier cave burial among ethnic groups in northern Sarawak that have had no such practice within the ethnographic present, and of earlier matrilineal descent among the patrilineal peoples of Malaita in the Solomon Islands, are presented in Blust (1986-87).

In dealing with the subset of kinship terminology relevant to the present argument I follow the approach to semantic reconstruction developed in Blust (1987a). A fundamental premise of this approach is that true synonymy is rare, and should not be lightly assumed in the glossing of reconstructed morphemes.

\subsection{SUBGROUPING}

The problem of linguistic subgrouping can be formulated as the following question. Given three languages A, B and C which are known to be genetically related (e.g. Icelandic, English and French) is there a basis for concluding that two of the languages are more closely related to one another than either is to the third? The importance of subgrouping to reconstruction has been appreciated at least since the Neogrammarians (last quarter of the nineteenth century), and the principles which govern the evaluation of subgrouping evidence were first clearly enunciated during the same period. Briefly, only linguistic innovations (changes in phonology, morphology, lexicon, syntax or semantics) can be used as reliable

interpretation, rather than simply assuming (as Blust implicitly does) that current usages will directly reflect a single, original system at the most inclusive level". Not only have I never advocated such an approach to semantic reconstruction, but it is rather well known that I have argued vigorously against it (Blust 1987a). 
evidence for subgrouping, common retentions telling us nothing about a period of exclusively shared history. The factor which most of ten interferes with straightforward application of the comparative method and the determination of exclusively shared innovations is borrowing. However, borrowing is far more likely to affect semantic domains which can be characterised broadly as 'cultural' than the semantic domains represented by 'basic vocabulary' (body parts, pronouns, low numerals, basic kin terms, words for everyday universal natural phenomena, etc.). A second factor which complicates the problem of linguistic subgrouping is drift, or independent parallel development. This is discussed in section 3.4 .

Greenberg (1957:46ff.) points out that the problem of subgrouping genetically related languages is often far more difficult than the problem of establishing the primary fact of relationship. This has certainly been true in Austronesian, as the broad membership of the family (exclusive of the Formosan languages) has been known since the second voyage of Cook (1772-75), yet no comprehensive subgrouping was undertaken until that of Dyen (1965b). Dyen's classification was based on the then new and largely untested method of lexicostatistics, and it thus constituted not only a major application of the method to a particular family of languages, but also an important test of the validity of lexicostatistics in general.

Although the results of Dyen's classification were initially greeted with some enthusiasm (e.g. Murdoch 1964), today virtually all Austronesian comparativists reject his family tree, both with reference to its major branches, and to many of its finer ramifications. It is now evident that in determining such major groupings as the 'Malayo-Polynesian Linkage' Dyen was simply misled by the failure of lexicostatistics to distinguish innovations from retentions. Languages which are demonstrably more conservative in the rate at which they have replaced basic vocabulary (e.g. Malay, Tagalog, the Polynesian languages) were thus grouped together despite a total absence of qualitative evidence for such a grouping, and indeed a good deal of qualitative evidence which is directly at odds with it (Grace 1966, Bellwood 1979:124ff.).

The following subgrouping of Austronesian is now accepted, in whole or in part, by a number of scholars working within the fields of Austronesian linguistics, and of general linguistics: (1) Austronesian (AN) divides into Formosan (one or more primary subgroups in Taiwan) and Malayo-Polynesian (MP: all non-Formosan AN languages), (2) MP divides into Western Malayo-Polynesian (WMP: AN languages of the Philippines, western Indonesia, mainland Southeast Asia and Madagascar, together with Palauan and Chamorro of western Micronesia) and Central-Eastern Malayo-Polynesian (CEMP), (3) CEMP divides into Central Malayo-Polynesian (CMP: AN languages of the Lesser Sunda and Molucca Islands from Bimanese in the west through Aru and thence northwards through the central Molucca Islands inclusive of the Sula Archipelago), and Eastern Malayo-Polynesian (EMP), (4) EMP divides into South Halmahera-West New Guinea (SHWNG: AN languages of Halmahera, the Raja Ampat Islands and the Vogelkop Peninsula of New Guinea as far east as Waropen) and Oceanic (OC), (5) OC includes over 450 languages in Melanesia, Micronesia and Polynesia. The languages of the Bomberai Peninsula (Irian) are insufficiently known to permit secure subgrouping, but preliminary data suggest that some of these, including at least Sekar, Onin and Uruangnirin, are CMP, while others (as Irahutu) may constitute a primary branch of the SHWNG group (Blust 1993). The position of Yapese (western Micronesia) within MP is unclear. 
This subgrouping was challenged by Aberle (1980) who, however, did so without any reference to the relevant literature or supporting evidence. The Oceanic node was first demonstrated by Dempwolff (1937), and is now so well established as to require little comment. Arguments in support of EMP are presented in Blust (1978a), arguments in support of CEMP in Blust (1974a, 1983-84b, 1993), and arguments in support of MP in Blust (1977a, 1992a). This view of subgrouping relationships in Austronesian has not been without its critics (most notably Isidore Dyen), but it has been adopted almost unchanged by Bellwood (1985:107ff.), Ruhlen (1987) and Clark (1992). In a recent publication Grace (1990:160) refers to "Robert Blust's classification, which appears to be accepted at least as a working hypothesis by the majority of Austronesianists".

The point of the preceding paragraph is to make it clear to the uninformed reader that the subgrouping adopted in this paper (1) is supported by a good deal of published data and argumentation, and (2) is independent of the argument presented here.

\subsection{DRIFT}

The term "drift" was introduced into the linguistic literature by Edward Sapir (1921) in connection with observations about the history of pluralising umlaut in the Germanic languages. Sapir pointed out that both English and High German have undergone a series of changes in which an old plural suffix *-i was weakened (in German) or lost (in English), but only after transferring the grammatical information that it had originally carried to the vowel of the nominal stem through the phonological process of umlaut. As a result of this process irregular singular : plural forms of the type mouse : mice arose in English and parallel singular : plural forms of the type Maus : Mäuse arose quite independently in High German (but not Low German). Given the fairly detailed agreement in the form of this change one would normally consider it simplest to assume that it took place once in the common ancestor of both languages. Instead, Sapir argued that the change was completely independent in the two closely related languages, having begun in each after their separation and the transplantation of English from the European mainland to the British Isles.

Leonard Bloomfield, Sapir's contemporary and competitor for the leadership of American linguistics throughout the 1920s and 1930s, treated the idea of drift with the same scepticism that he reserved for 'mentalistic' concepts in descriptive linguistics. To him drift was a 'mystical' concept not worthy of serious scientific study.

Time has shown the importance of Sapir's insight. Other instances of drift, both large and small, have been documented and their theoretical significance discussed by linguists with a variety of theoretical persuasions, including Hockett (1948), Greenberg (1957), Vennemann (1975), Blust (1978b:117ff., 1990), Malkiel (1981) and Donegan and Stampe (1983). The common view of these and other scholars who have written on the subject is that drift (Malkiel prefers to call it "slant") is a product of the independent operation of inherited structural pressures in languages that have separated from a common ancestor. The consequence of this shared set of constraints and tendencies is an increased likelihood for historically independent changes to follow similar lines of development in genetically related languages. Understandably, all linguistic examples of drift that have been described to date appear to be motivated by structural pressures of language organisation. In this paper, however, I argue for the first reported case of a linguistic drift that is motivated by structural pressures of social organisation. 


\section{BRIEF SUMMARY}

To assist the reader in following the main outlines of the argument, I briefly summarise in this section the major observations which provide its empirical substance.

It is important for the anthropologist reader to recognise that the inferences reached in this paper do not depend in any way on a particular model of how systems of asymmetric alliance work. All that the reader must allow in order to accept my inference that PMP society had descent groups is: (1) the correlation between type of sibling terminology and type of descent reported cross-culturally by Murdock (1968); (2) the 'uniformitarian hypothesis' that correlations between features of terminology and type of descent which hold in the present also held in the past; and (3) my reconstruction of a cross/parallel distinction in the PMP sibling terminology. In short, if the cross/parallel distinction shows a statistically significant correlation with the presence of descent groups, as Murdock claims to have demonstrated, and such correlations as hold in the present also held in the past, then the presence of a reconstructed cross/parallel distinction in the PMP sibling terms clearly supports a probabilistic inference that descent groups were present in PMP society.

For my second inference (that a form of matrilateral cross-cousin marriage was a dominant PMP organisational ideal) the reader need only accept the following propositions: (4) the PMP terms for cross-siblings were *ñaRa 'B (w.s.)' and *betaw ' $Z$ (m.s.)'; (5) these semantically non-derivative, monomorphemic terms were replaced in some WMP languages, some CMP languages, and all OC languages by terms which had the primary meanings 'male/female' or 'male child/female child'; (6) PMP *anak 'child' meant not only 'offspring', but also 'member of a social group'; (7) in systems of dual cosmological classification universally the classificatory category 'male' aligns with 'wife-giver' and the classificatory category 'female' with 'wife-taker'; and (8) PMP *anak ma-Ruqanay/laki ('child/group' + 'male') and *anak bahibabahibinahi ('child/group' + 'female') referred not to crosssiblings, but rather to wife-givers and wife-takers respectively, as attested wholly or in part in such contemporary languages as Karo Batak and Dairi-Pakpak Batak of Sumatra, Manggarai, Atoni and Tetun of the Lesser Sunda Islands, and Huaulu of the Molucca Islands.

Finally it must be pointed out that the two inferences which I have proposed (presence of descent groups, adherence to an ideal of matrilateral cross-cousin marriage) are logically independent. Although the evidence for each overlaps in my reconstruction of a cross/parallel distinction in the PMP sibling terminology, the first inference is based entirely on points (1), (2) and (3), and these points in themselves imply nothing about a marriage rule.

\section{PROTO MALAYO-POLYNESIAN SIBLING TERMS}

In his pioneering but outdated comparative dictionary, based on data from eleven of the more than 900 Austronesian languages, Dempwolff (1938) reconstructed four terms for siblings. In Dyen's orthography they are: $(1) * a(n) j i$ 'consanguineal relative (generally younger)'; (2) *betaw 'sibling of the opposite sex'; (3) * $q a(n) j i$ 'consanguineal relative (generally of the opposite sex)'; and (4) *kaka 'elder sibling'. The first and third items were erroneously reconstructed as doublets because of Dempwolff's failure to deal adequately with the correspondences that Dyen (1953b) assigned to ${ }^{*} q,{ }^{*} h$ (later rewritten ${ }^{*} S$ ) and zero. This leaves three PMP terms, now written *hua(n)ji, *betaw and *kaka. 
It is clear that Dempwolff's reconstructed terms do not form a coherent system def inable in terms of relative or absolute sex, relative age or other features that are commonly used to generate systems of sibling terminology (Nerlove \& Romney 1967, Murdock 1968). Most notably, Dempwolff found no comparative evidence in the eleven languages he considered for reconstructing: (1) a second monomorphemic cross-sibling term, or (2) two additional semantically derivative or morphologically complex cross-sibling terms, both of which are revealed by wider comparison. I refer to the monomorphemic expressions as "historically primary', and the semantically derivative or morphologically complex expressions as 'historically secondary' cross-sibling terms respectively.

\subsection{THE HISTORICALLY PRIMARY SIBLING TERMS}

Table 2 presents evidence which justifies the reconstruction of four PMP sibling terms: *betaw 'sister (man speaking)', *ñaRa 'brother (woman speaking)', *kaka/aka 'elder sibling' and *hua(n)ji 'younger sibling', the latter two possibly restricted to siblings of the same sex. The languages from which data is cited are segregated into three major subgroups: Western Malayo-Polynesian (WMP), Central Malayo-Polynesian (CMP), and Oceanic (OC). In a few cases it has been necessary to infer the probable gloss of a term from the gloss actually given, although as a rule I have adhered closely to my sources even where there are grounds for questioning them (cf. Appendix). ${ }^{12}$

TABLE 2: EVIDENCE FOR THE HISTORICALLY PRIMARY PMP SIBLING TERMS

*betaw

WMP:

Berawan (Long Terawan) betaw 'sister' (1)

Ngaju Dayak betaw 'sister, man speaking' (2)

Toba Batak i-boto 'sibling of opposite sex' (3)

Simalungun Batak botow 'sibling of opposite sex'

CMP:

Manggarai weta 'sister, man speaking'

Ngadha veta 'sister, man speaking'

Endeh veta 'sister, man speaking'

Waijewa woto 'sister, man speaking'

Roti foto 'sister, man speaking'

Tetun feto- $n$ 'sister, man speaking'

Alune beta 'sibling of opposite sex'

Soboyo foto 'sister, man speaking'

(2) * ${ }^{n} a R a$

WMP:

Ngaju Dayak ñahE'3 'brother, woman speaking' (2)

12 Cases where I question (but accept) the source appear in the Appendix with a parenthesised alternative gloss followed by a question mark, as with Maranao kaka 'elder' (= e//?). Cases where I reinterpret (and hence reject) the gloss given by the source appear with a parenthesised alternative gloss not followed by a question mark, as with Maranao babai ' $\mathrm{Z}$ ' $(=\mathrm{xf})$. For a justification of the segmentation of initial * $t$-, and of final * $*_{-}$and $*_{-}$? see Blust (1979).

13 For typographical convenience I use 'E' for Hardeland's (1859) digraph. 
CMP:

Komodo na 'brother, woman speaking'

Manggarai nara 'brother, woman speaking'

Ngadha nara 'brother, woman speaking'

Endeh nara 'brother, woman speaking'

Sika nara 'brother, woman speaking'

Solorese naa 'brother, woman speaking'

Waijewa na?a 'brother, woman speaking'

Roti na 'brother, woman speaking'

Tetun naa- $n$ 'brother, woman speaking'

Erai nara-n 'sibling of opposite sex'

Leti nara 'sibling of opposite sex'

Wetan nara 'sibling of opposite sex'

Soboyo naha 'brother, woman speaking'

(3)

*kaka/aka

WMP:

\section{PHILIPPINES}

Ivatan kaka 'elder sibling' (4)

Botolan Sambal kaka-? 'elder sibling'

Kalamian Tagbanwa aka-? 'elder sibling'

Umirey Dumagat kaka 'elder sibling'

Casiguran Dumagat aka 'elder sibling'

Atta kaká 'elder sibling'

Ata Manobo kako-y 'elder sibling of same sex' (5)

Cotabato Manobo kaka-y 'elder sibling of same sex'

Samal si-aka 'elder sibling'

WESTERN INDONESIA

Ngaju Dayak kaka 'elder sibling'

Ngaju Dayak aka 'elder sibling'14

Malay kaka-k 'elder sibling'

Toba Batak haha 'elder sibling of same sex'

Dairi-Pakpak Batak kaka 'elder sibling of same sex'

Simalur kaka-? 'elder sibling'

Nias $k a$ ? a 'elder sibling'

Mentawai kaka 'elder sibling'

Middle Malay kaka-? 'elder sibling'

Old Javanese kaka- $\eta$ 'elder sibling'

Javanese kaka- $\eta$ 'elder sibling'

Sasak kaka-? 'elder sibling'

14 According to Hardeland (1859) /aka/ refers to one's own elder sibling, while /kaka/ is used in general reference. Durdje Durasid, a native speaker of the Katingan dialect of Ngaju Dayak, maintains that /kaka/, /aka/ and /andi/ are tenms of reference for parallel siblings only, but are terms of address/vocatives for both cross and parallel siblings. Thus, a man calls/addresses his eZ as /kaka/, but refers to her as /betaw/, but he both calls and refers to his eB as /kaka/. According to Durasid, /kaka/ and /aka/ are synonymous, but /ak: $\mathbf{a}$ connotes greater affection. In addition, a third person may use yarig as a tenn of reference for a younger parallel sibling, as when a father speaks to his older son about the latter's younger brother. 


\section{SULAWESI}

Sangir kaka-?/aka- $\eta$ 'elder sibling of same sex'15

Tondano kaka-? 'elder sibling'

Bare'e tu-kaka 'elder sibling'

Tae' kaka-? 'elder sibling'

Mori aka 'elder sibling'

Makassarese kaka-? 'elder sibling'

Wolio aka 'elder sibling'

CMP:

Komodo ha(ha) 'elder sibling'

Manggarai $\mathrm{ka}^{2} \mathrm{e}^{16}$ 'elder sibling of same sex'

Ngadha kae 'elder sibling'

Endeh $\mathrm{ka}$ ?e 'elder sibling of same sex'

Solorese kaka 'elder sibling'

Roti $k a$ ?a 'elder sibling of same sex'

Wetan kaka 'elder sibling'

Fordat a?a 'elder sibling of same sex'

Paulohi $w$-aa 'elder sibling'

Soboyo kaka 'elder sibling'

OC:

Yabem kaka 'elder sibling of same sex (vocative)'

Manam a?a 'elder sibling of same sex (vocative)'

Motu kaka 'elder sibling of same sex'

Bugotu kaka 'elder sibling of same sex (vocative)'

(4) *hua(n)ji

WMP:

\section{PHILIPPINES}

Ivatan wari 'younger sibling' (4)

Botolan Sambal ali 'younger sibling'

Kalamian Tagbanwa ari-? 'younger sibling'

Umirey Dumagat weli 'younger sibling'

Casiguran Dumagat wadi 'younger sibling'

Ata Manobo hari 'younger sibling of same sex' (5)

Cotabato Manobo hadi 'younger sibling of same sex'

Maranao pag-ari 'brother, sister'

Samal si-ali 'younger sibling'

\section{WESTERN INDONESIA}

Miri $t$-adih 'younger sibling'

Bintulu $t$-arey 'younger sibling'

Ngaju Dayak andi 'younger sibling'

Ngaju Dayak pah-ari 'parallel sibling'

15 Steller and Aebersold (1959) give aka- $\eta$ as 'the elder of two brothers or sisters' and kaka as 'eB', 'eZ'. The restriction to parallel siblings thus appears to apply only to the first term.

16 Manggarai, Endeh $/ \mathrm{ka}^{7} \mathrm{e} /$, Ngadha $/ \mathrm{kae} /$ cannot regularly reflect ${ }^{*} k a k a$. They may be irregularly reshaped reflexes of *kaka, or unrelated forms which show a superficial resemblance to the expected reflex of this item. 
Rhacle adei 'clan, blood relative (usually younger)'

Malay adi-k 'younger sibling'

Toba Batak angi 'younger sibling of same sex'

Dairi-Pakpak Batak aggi 'younger sibling of same sex'

Simalur axi 'younger sibling'

Nias achi 'younger sibling'

Middle Malay adi- $\eta$ 'younger sibling'

Mentawai bagi 'younger sibling'

Old Javanese ari 'younger sibling'

Javanese ari 'younger sibling'

Sasak adi-? 'younger sibling'

\section{SULAWESI}

Sangir $t$-uari 'younger sibling'

Tondano rari 'younger sibling'

Bare'e tu-a?i 'younger sibling'

Tae' adi 'younger sibling'

Mori wai 'younger sibling'

Makassarese andi-? 'younger sibling (less refined)'

Makassarese ari 'younger sibling (more refined)'

Wolio andi 'younger sibling'

CMF:

Komodo ari 'younger sibling'

Manggarai ase 'younger sibling of same sex'

Ngadha azi 'younger sibling'

Endeh ari 'younger sibling of same sex'

Solorese ari- $n$ 'younger sibling'

Kambera eri 'younger sibling of same sex'

Roti fadi 'younger sibling of same sex'

Wetan yari 'younger sibling'

Fordat wari 'younger sibling of same sex'

Kei wari-n 'younger sibling of same sex'

Paulohi wari 'younger sibling'

OC:

Yabem l-asi 'younger sibling of same sex'

Manam $t$-ari 'younger sibling of same sex'

Motu $t$-adi 'younger sibling of same sex'

Bugotu $t$-ahi 'younger sibling of same sex'

In the above citations I have tried to group together only terms which belong to the same cognate set, regardless of their meaning. In a few cases the forms cited may in fact not be cognate, as with Manggarai, Endeh / ka?e/, Ngadha /kae/ 'elder sibling of the same sex', cited under *kaka. In virtually every other case the phonological correspondences relating the attested forms to their reconstructed prototypes can be shown to be recurrent. This remark may require a note of explication.

My Ngaju Dayak material, like that of Dempwolff and Dyen before me, comes from the classic dictionary of Hardeland (1859), in which two 'speech strata' were recognised by Dempwolff (1937) and reinterpreted by Dyen (1956). Ngaju Dayak -/E/ is the normal reflex 
of PMP *-a in the 'old speech stratum', while -/a/ is the corresponding 'new speech stratum' reflex (Dyen 1956). Since 'new speech stratum' forms generally are believed to be products of borrowing from Banjarese Malay it is possible that Ngaju Dayak /kaka/ is a Banjarese loan. However, the occurence of the variant /aka/, which is not reported for Banjarese or other Malay dialects, raises doubts about this suggestion. Furthermore, Hudson (1967) lists kinship terms for several Ngaju dialects, including Kapuas /kaka?/ 'elder sibling', /ñaha?/ 'brother' (implied, but not stated to be from the standpoint of a female speaker), and Katingan /kaka-k/ 'elder sibling', /ñaha-i/ 'brother' (explicitly stated to be from the standpoint of a female speaker). Hudson's Katingan terms for 'elder parallel sibling' and 'brother of a woman', like the similar terms given by Hardeland, have different endings, but his Kapuas terms do not. These problems remain unresolved, but hardly cast serious doubt on the Ngaju Dayak contribution to the reconstruction of ${ }^{*} \tilde{n} a R a$ and ${ }^{*}$ betaw.

Reflexes of PMP *hua(n)ji (PAN *Suaji) are quite varied, for the following reason. Although PAN $* S$ is preserved as a sibilant in most Formosan languages, outside Taiwan the initial consonant of ${ }^{*}$ Suaji has become $/ \mathrm{h} /$ in the central and southern Philippines, and disappeared almost everywhere else. Where it disappeared the resulting / $\mathrm{u} /$ before a low vowel often semivocalised, yielding a historically secondary form ${ }^{*} w a(n) j i$ which then underwent the same changes as forms with original $*_{w}$ - (e.g. Mentawai, with $*_{w}>/ \mathrm{b} /$, Rotinese, with ${ }^{*} w>$ /f/). In a few Philippine languages, particularly in Mindanao, the expected reflex inexplicably fails to show /u/ (e.g. Ata Manobo, where we would expect **huari, not the attested /hari/). Finally, as noted in Blust (1979), reflexes of PAN *Suaji (and of various other kinship terms) sometimes contain a vocative prefix ${ }^{*} t$ -

If cognate sets (1)-(4) are mapped onto the Austronesian family tree described in section 3.3 , it is apparent that their prototypes must have been found in the common ancestor of the WMP and CMP languages (Proto Malayo-Polynesian). Our next task is to assign meanings to these four PMP forms.

One way to gloss PMP *betaw, *ñaRa, *kaka and *hua(n)ji would be to count semantic reflexes and determine meaning by majority rule. This is essentially the approach of Marshall (1984), who concludes that Proto Oceanic (he does not use the term) made only a cross/parallel distinction in sibling terms, since this is numerically the most frequent pattern that he found in his data sample. As Bender (1984), Blust (1984a), Chowning (1984) and Clark (1984) have all pointed out, this analysis fails to explain why, if a relative age distinction did not exist in the parallel sibling category in Proto Oceanic, reflexes of POC *toka (reference) or *kaka (vocative) always indicate the elder sibling, and reflexes of POC *tansi always indicate the younger sibling in terminologies which distinguish relative age among parallel siblings. In fact, Marshall's analysis completely ignores the well-known methodological distinction between typological comparison, which aims at the establishment of universal associations together with implicational relationships, and genetic comparison, which aims at the establishment of specific historical connections.

An alternative approach to glossing reconstructed forms which does pay close attention to the difference between the comparison of structural categories (= typological comparison) and the comparison of cognate forms, is that of Dyen and Aberle (1974). As noted in Blust (1987a) the Dyen-Aberle approach is not one in which semantic categories are reconstructed in the same sense in which phonemic forms are reconstructed. Rather, it is an approach in which reconstructed phonemic forms are matched with semantic categories that are given in 
advance. Functionally, the most important concept in the Dyen-Aberle method is the concept of 'inclusion'. According to Dyen (in Dyen \& Aberle 1974:17):

If a candidate $c$ appears in a list of subgroups $L_{1}$ in meaning $M_{1}$ and also in a different list of subgroups $L_{2}$ in meaning $M_{2}$, then if $L_{2}$ contains all of the subgroups of $L_{1}$ and at least one subgroup in addition, $L_{2}$ is said to include $L_{1}$; our practice is to say that the particular candidate $c$ in $\mathrm{M}_{2}$ INCLUDES the candidate $c$ in $\mathbf{M}_{1}$.

In more conventional language the Dyen-Aberle principle of inclusion maintains that if a reconstructed form has more than one semantic reflex that reflex which is found in a larger number of primary subgroups is to be assigned to it, while competing semantic reflexes which are found in a smaller number of primary subgroups are to be treated as innovations. Semantic reflexes which have an equivalent distribution over primary subgroups are said to be unincluded; all unincluded meanings are assigned to the reconstructed form that they reflect, no matter what the number of such meanings (Dyen \& Aberle 1974:18).

Table 2 presents an array of sibling terms in Austronesian languages with whole glosses. To a greater or lesser extent all of these glosses encompass more than one category of kin. To ensure that the Dyen-Aberle approach receives due consideration Table 3 reformulates the material of Table 2 to highlight the distribution of candidate terms (CT) over primary sibling categories (PSC). Only common glosses (represented by the number in parentheses following the glosses in Table 2) are displayed in Table 3:

TABLE 3: DISTRIBUTION OF FOUR PMP CANDIDATE TERMS OVER PRIMARY SIBLING CATEGORIES

PSC

CT

WMP

CMP

OC

(m.s.)

eB

1

2

betaw

$\tilde{n} a R a$

3

4

kaka/aka

hua(n)ji

4,5

4,5

yB

1

eZ

betaw

$\tilde{n} a R a$

kaka/aka

hua(n)ji
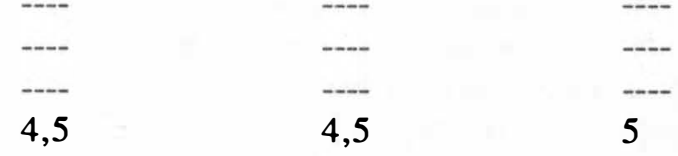

4,5

5

betaw

$\tilde{n} a R a$

kaka/aka

$1,2,3$

2,3

$h u a(n) j i$

4

3

4

$1,2,3$

2,3

ña

kaka/aka

hua(n)ji

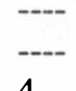


(w.s.)

$\mathrm{eB}$

1

2

3

4

yB

1

2

3

4

$\mathrm{eZ}$

1

2

3

4

yZ

1

2

3

4 betaw

$\tilde{n} a R a$

kaka/aka

hua(n)ji

betaw

$\tilde{n} a R a$

kaka/aka

hua(n)ji

betaw

$\tilde{n} a R a$

kaka/aka

hua(n)ji

betaw

$\tilde{n} a R a$

kaka/aka

hua(n)ji
3

2

4

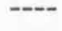

3

2

4

1

4,5

----

1

$-$

4,5
3

2,3

4

3

2,3

4

$--$

$\begin{array}{ll}- & - \\ -- & 5 \\ -- & -\end{array}$

4,5

Applied to the data at hand the Dyen-Aberle approach to glossing reconstructed forms would require us to assign the following glosses to items (1)-(4): (1) *betaw 'cross-sibling', supported by Toba Batak (WMP) and Alune (CMP); also ' $\mathrm{Z}$ (m.s.)', supported by Ngaju Dayak (WMP), and by many CMP reflexes; (2) *ñaRa 'B (w.s.)', supported by Ngaju Dayak (WMP) and by many CMP reflexes; (3) *(k)aka 'elder sibling of the same sex', supported by Ata Manobo, Toba Batak, Dairi-Pakpak Batak, Sangir and several CMP reflexes (also 'elder sibling', supported by Komodo, Ngadha, Solorese, Wetan, Paulohi, Soboyo and many WMP reflexes); and (4) *hua(n)ji 'younger sibling of the same sex', supported by Ata Manobo, Toba Batak, Dairi-Pakpak Batak and several CMP reflexes (also 'younger sibling', supported by Komodo, Ngadha, Solorese, Wetan, Paulohi and many WMP reflexes). As I have argued elsewhere (Blust 1980b, 1987a) there are inherent limitations to the Dyen-Aberle method of "lexical reconstruction", which is concerned exclusively with what Saussure called the semantic "signification" of linguistic forms, as opposed to their semantic 'values'. As it happens, in this particular set of data the DyenAberle approach comes closer to achieving satisfactory semantic coherence than is sometimes the case. However, it is evident that *betaw could not have meant both 'cross-sibling' and ' $\mathrm{Z}$ (m.s.)', especially in view of the fact that the only gloss which can be assigned to * $\tilde{n} a R a$ is 'B (w.s.)'. PMP *betaw must have meant ' $\mathrm{Z}$ (m.s.)', and *ñaRa 'B (w.s.)', as their reflexes still do in Ngaju Dayak and in many CMP languages extending from Komodo in the western Lesser Sunda Islands to the Sula Archipelago in the north-central Molucca Islands.

By contrast to PMP *betaw and *ñaRa, the meaning of PMP *kaka/aka and *hua(n)ji remains an unresolved issue. In past work I have tended to assume a model of lexical categorisation in which semantic space is exhaustively partitioned into mutually exclusive categories. Systems of sibling terminology such as that of the Ngaju Dayak appear to 
contradict this model, since according to Hardeland (1859) NgD betaw means ' $\mathrm{Z}$ (m.s.)' and ñahE means 'B(w.s.)', but kaka/aka means 'eB' or 'eZ' and andi means 'yB' or 'yZ', without regard to sex of speaker (pahari means 'parallel sibling', without regard to relative age). In other words, some relationships may be expressed by two terms, presumably carrying different emphases (e.g. in Ngaju Dayak a man may call his eZ either betaw, emphasising the difference of sex, or aka, emphasising the difference of age, but may call his $\mathrm{eB}$ only aka). The difficulty with accepting this characterisation of the use of semantic space more generally is that the description of many terminologies in the literature is known to be inexplicit. For example, Koentjaraningrat (1972:82), drawing on an earlier report by Coolhaas, gives Manggarai $k a$ ?e as 'eB, FBS, MZS' and Manggarai ase as 'yB', but the more complete information provided by Verheijen (1970:100-101) and Gordon (1980:51-52) shows clearly that these terms are restricted to parallel siblings (and some other relationships not relevant to the present discussion). For these reasons I will leave open the question whether PMP *kaka/aka and *hua(n)ji applied exclusively to parallel siblings, or to siblings in general. In either case relative sex is a necessary component of the definition of PMP *betaw and * $\tilde{n} a R a$, and the PMP system must, therefore, be classed as a further subtype of Murdock's (1968) "Melanesian, or Relative Sex Type” of sibling terminology.

Another issue that may be raised in connection with the foregoing reconstruction is its critical dependence upon the Ngaju Dayak evidence. Virtually all CMP-speaking societies for which information is available have a terminological contrast for parallel and cross-siblings, and the terms *betaw and ${ }^{*} \tilde{n} a R a$ can easily be reconstructed for Proto Central MalayoPolynesian. As several writers have noted, however, the parallel/cross contrast is rare in societies that speak WMP languages. All four Ngaju Dayak terms are cognate with the sibling terms of such CMP languages as Rotinese, and have essentially the same semantic values. Neither chance nor borrowing of fers a plausible explanation for this agreement, and we are therefore forced to conclude that the Ngaju Dayak system, rare as it is among WMPspeaking peoples today, must be a retention of a system of sibling terminology that was once much more widespread in the Philippines and western Indonesia. This inference receives tangential support from the terminological systems of the Batak peoples of northern Sumatra, where Toba Batak /i-boto/, Simalungun Batak /botow/ 'cross-sibling' preserve a reflex of *betaw, albeit one that has undergone a widening of reference to include kin types that were originally subsumed by *betaw and ${ }^{*} \tilde{n} a R a$ together. A similar (historically independent) widening of reference is seen in Alune (CMP) /beta/ 'cross-sibling'. Finally, the Berawan dialect of Long Terawan in northern Sarawak preserves another component of the original meaning of *betaw in the form /betaw/ 'sister' (Proctor 1979). ${ }^{17}$

Even with some indeterminacy regarding the scope of reference of PMP *kaka/aka and *hua(n)ji, the foregoing reconstruction of four PMP sibling terms distinguished by relative sex and relative age serves to remedy the muddled state of affairs found in Dempwolff (1938). Having said this it is legitimate to ask: "what have we achieved through this

17 It is unclear whether this form is adequately glossed. When I worked briefly with a Long Terawan speaker during iny fieldwork in northern Sarawak in 1971 I recorded only /tukeh/ 'elder sibling', /taréh/ 'younger sibling' and /padi?/ 'sibling (in general)'. Proctor's /betaw/ suggests that Long Terawan may in fact have a cross/parallel distinction in the sibling terminology that has until now gone unnoticed. The gloss that he provides for /betaw/ probably should be regarded as untrustworthy because of the all-pervasive gender bias that is commonly seen in the collection of kinship terms that make use of relative sex. Most fieldworkers, both anthropologists and linguists, are male, as are their informants. In such a situation if any cross-sibling term is collected one would expect it tobe the term for ' $\mathrm{Z}$ (m.s.)'. 
reconstruction towards understanding the evolution of social organisation in Austronesianspeaking societies over approximately the past five millenia?".

Murdock (1968) answers this question for us. In a globally representative sample of 800 societies selected from the ethnographic literature (mostly in English, German and French), he has isolated seven major types of sibling terminology. His Type F, the "Melanesian, or Relative Sex Type" shows a statistically significant positive correlation with the presence of descent groups (in particular matrilineal descent groups). The clear inference from his tables of correlations (especially his Table 2), is that Proto Malayo-Polynesian society had descent groups - that is, corporate kin groups defined in terms of an apical ancestor.

\title{
5.2 THE HISTORICALLY SECONDARY SIBLING TERMS
}

If the foregoing reconstruction of PMP sibling terms was all that could be achieved through comparative linguistics it would indisputably be of some value to ethnology, but it would not represent a major triumph of linguistic methodology in addressing diachronic problems of social anthropology. What makes the comparative study of sibling terms in Austronesian far more interesting and methodologically important is the existence of a second set of terms for the cross-siblings which is even more widespread than the reflexes of *betaw and ${ }^{*} \tilde{n} a R a$. In some cases this second set of cross-sibling terms involves true cognates, but in others it involves only lexical items of similar semantic structure. For reasons that will become apparent, these terms can be characterised as semantically derivative or morphologically complex. Significantly, no such competing comparisons exist for the terminology relating to parallel siblings. Consider the material of Table 4, organised as in Table 2. Literal morpheme glosses, which are given in parentheses, are: $\mathrm{M}=$ male, $\mathrm{F}=$ female, $\mathrm{C}=$ child, $\mathrm{x}=$ cross-sibling. Reconstructed morphemes are: PMP *ma-Ruqanay 'male', PMP *laki 'male (probably originally of animals)', PMP *anak 'child; member of a social group', PMP *bahi/ba-bahi/b-in-ahi/ba-b-in-ahi 'female': 18 forms in square brackets are non-cognate, but exhibit a parallel semantic derivation.

\section{TABLE 4: EVIDENCEFOR THE HISTORICALLY SECONDARY CROSS-SIBLING TERMS}

\author{
*(anak) bahi 'Z (m.s.)' \\ WMP: \\ PHILIPPINES \\ Bontok ka-babai-an (F) \\ [Ilongot bekur] (F) \\ Maranao bebai (F) \\ [Tiruray libun] (F) \\ WESTERN INDONESIA \\ Malagasy ana bavy (CF) \\ [Middle Malay kelaway] (F)
}

18 For the complex problem of reconstructing the PAN word for 'female' cf. Blust (1982c). Like the word for 'female', the word for 'male' can be reconstructed both as a simple stem and as an affixed form. Reflexes of the former include Paiwan /uqaLay/, Palauan /sechál/ and Manggarai /rona/ (all < *RuqaNay); reflexes of the latter include Bintulu/manay/, Balinese /muani/, Sangir /mahuane/, Tae' /muane/, Kambera /mini/, Motu /maruane/, Mono-Alu /manuale/ (< Met.), Tongan /ga?ane/ and a number of other forms cited here as components of cross-sibling terms (all < *ma-RuqaNay). 
Bolaang Mongondow bobai (F)

[Tae' anak dara] ${ }^{19}$

CMP:

Sika whine $(\mathrm{F})$

Adonara bine (F)

Kambera ana wini (CF)

Savu na weni (CF)

[Leti nara puate] (xF)

OC:

Bileki hata vile (xF)

Bangasa vivini $(\mathrm{F})$

Eromanga veven $(\mathrm{F})$

Trukese feefiney $(\mathrm{F})$

Tongan tuo fefine (xF)

Hawaiian kua hine (xF)

(6) *(anak) ma-Ruqanay 'B (w.s.)'

WMP:

\section{PHILIPPINES}

Bontok ka-lalaki-an (M)

Ilongot raki (M)

Maranao laki (M)

Tiruray lagey (M)

WESTERN INDONESIA

Malagasy ana dahy (CM)

Middle Malay moanay (M)

Bolaang Mongondow lolaki (M)

Tae' anakmuane (CM)

CMP:

Kambera ana mini (CM)

Savı na mone (CM)

Leti naramuani (xM)

OC:

Bileki hatamale (xM)

Bangasa mani (M)

Eromanga man (M)

Trukese mwääni(M)

Tongan tuo ya?ane (xM)

Hawaiian kua nane (xM)

Some of the above terms contain cognate morphemes. Thus, for Proto Philippines it appears safe to reconstruct *babahi ' $\mathrm{Z}$ (m.s.)' and *laki ' $\mathrm{B}$ (w.s.)', based on cognate forms in the Cordilleran languages of northern Luzon and Maranao of southern Mindanao (with further support for the second term from Tiruray). Similarly, for Proto Oceanic, Milke

19 Literally 'child' + 'virgin/maiden'. 
(1938) reconstructed *vavine ' $\mathrm{Z}$ (m.s.)', *mane 'B (w.s.)', based on widely distributed cognates in the Oceanic languages.

At the Proto Malayo-Polynesian level, however, the reconstruction of such semantically derivative or morphologically complex alternative terms becomes more problematic. It is prima facie plausible to posit *anak ma-Ruqanay 'B (w.s.)', based on Tae' (WMP) /anak muane/ and Kambera (CMP) /ana mini/. For many of the other terms, however, there is a lack of true cognation, as with the Malagasy terms /ana bavy/ ' $\mathrm{Z}$ (m.s.)', /ana dahy/ 'B (w.s.)', next to Kambera /ana wini/ ' $\mathrm{Z}$ (m.s.)', /ana mini/ 'B (w.s.)'. Rather than true cognation what these terms share is a common semantic history, that is, a historical derivation from terms the primary sense of which is 'male/female', or the morpheme meaning 'child' plus one of these gender modifiers. The former, semantically derivative type, based on the morphemes meaning 'male' or 'female', includes WMP, CMP and OC languages, while the latter, morphologically complex type ('child' + 'male/female') includes only WMP and CMP languages. In either case the material in Table 4 presents us with terms that compete with the monomorphemic and semantically derivative cross-sibling terms that have already been proposed. Following the Dyen-Aberle method of lexical reconstruction, but my subgrouping of Austronesian, we would be forced to reconstruct both PMP *betaw and *(anak) bahi in the meaning ' $\mathrm{Z}$ (m.s.)', and both PMP * $\tilde{n} a R a$ and *(anak) maRuqanay/laki in the meaning 'B(w.s.)'. If WMP and CMP languages are assigned to a single subgroup coordinate with Oceanic, as proposed by Dyen (1985), these semantically derivative and morphologically complex forms become the sole PMP candidates for the meanings ' $\mathrm{Z}$ (m.s.)' and ' $\mathrm{B}$ (w.s.)'.

The first point to note about comparisons (5) and (6) is that they provide an independent line of evidence indicating a cross/parallel distinction in the sibling terminology of Proto Malayo-Polynesian, hence strengthening our inference that descent groups were present in PMP society.

The second point to note about comparisons (5) and (6) is that they are either semantically derivative (derived from terms that carry the primary sense 'male/female') or morphologically complex. While the extension of terms that carry the primary sense 'male/female' to ' $\mathrm{B} / \mathrm{Z}$ ' is not surprising, the similar extension of terms that include the morpheme 'child' certainly is. Indeed, there is no obvious social structural reason why a reflex of PMP *anak 'child' would form part of any sibling term. I will refer to the seeming obscurity of this historical derivation as a problem of 'morphological opacity'.

The third point to note about comparisons (5) and (6) is that when reflexes of *anak plus an apparent gender modifier are possessed it becomes clear that they do not have a headmodif ier structure. For Tae', van der Veen (1940:17ff.) cites /anak muane-na/ 'her brother', but /anak-ku muane/ 'my son' (cf. /anak-na tau/ 'someone else's child' as evidence that the first and third person singular possessive markers do not differ positionally). Fischer (1957:5, note), citing Onvlee, makes a parallel observation about Kambera: "Referring to a brother the words ana and miniare seen as an inseparable whole, while as an indication for a son they are two. A woman speaking of her brother will say anaminingu (= 'my brother') while speaking of her son she will use the possessive form anangu mini, my son". Together these observations on the syntax of possession in Tae' (a WMP language), and Kambera (a CMP language) show unmistakeably that PMP *anak ma-Ruqanay had two functions: (1) it was a head-modifier construction meaning 'son', and (2) it was a syntactic unit with some other, as yet undetermined, meaning. 
The fourth point to note about comparisons (5) and (6) is that they are found scattered among reflexes of ${ }^{*} \tilde{n} a R a$ and ${ }^{*}$ betaw in languages that are either closely related, or neighbours, or both. Thus Waijewa (west Sumba) has /woto/, /na?a/, while Memboro (north-west Sumba) has /ana wini/, /ana moni/ for the female and male cross-siblings respectively, and similarly with Roti /feto/, /na/ next to Savu/ana weni/, /ana mone/.20 In the most extreme cases several of the languages of eastern Flores and the Solor Archipelago have one term from each system, as with Sika /nara/ 'B (w.s.)', but /wine/ ' $Z$ (m.s.)' and Solorese /naa/ 'B (w.s.)', but /bine/ 'Z (m.s.)'.

The final point that I wish to make in this section is that no attested Austronesian-speaking society is known to have more than one term for either of the cross-siblings. To attribute both * ñaRa and *anak ma-Ruqanay to Proto Malayo-Polynesian in the meaning 'B (w.s.)' would be to posit a duplication of terms with the same semantic value that is unprecedented in any of the languages accessible to direct observation. Moreover, although *betaw is reflected with the meaning 'female' in some of the languages of the Lesser Sunda Islands the primary meaning of PMP * $\tilde{n} a R a$ and *betaw clearly was 'B (w.s.)' and ' $\mathrm{Z}$ (m.s.)'. In this sense these terms can be considered as semantically non-derivative. The matter is, of course, very different with the second set of cross-sibling terms, which have as their primary meaning either 'male/female' or a compound term containing a reflex of *anak 'child' plus 'male' or 'female'.

To conclude, despite the widespread occurrence of semantically derivative cross-sibling terms in Austronesian languages, I find no convincing basis for reconstructing forms with the semantic structure 'male/female' or 'child' + 'male/female' as cross-sibling terms in Proto Malayo-Polynesian. The total absence of attested languages with more than one set of crosssibling terms, and the semantically derivative or morphologically complex character of the forms subsumed under comparisons (5) and (6) strongly suggests that these terms have arisen independently in the meaning 'cross-sibling'. But if so, what is their historical source, and what was the dynamic that drove the speakers of widely separated languages to follow similar paths of replacing ${ }^{*} \tilde{n} a R a$ and ${ }^{*}$ betaw with terms that must earlier have had some other referent?

\section{THE CROSS-SIBLING SUBSTITUTION DRIFTS}

Terms for the wife-giving and wife-taking groups are known for only a small number of societies that are reported to practice asymmetric alliance. Where they are known, however, they exhibit an interesting correspondence to the terms for cross-siblings. Examples are:

(1) KARO BATAK (northern Sumatra): /kalimbubu/ 'wife-givers' (no other clearly related meaning known); /anak beru/ (lit. 'child' + 'female') = 'wife-takers' (Neumann 1951, Singarimbun 1975, Needham 1978)

(2) DAIRI-PAKPAK BATAK (northern Sumatra): /kula kula/ 'wife-givers' (no other clearly related meaning known); /anak hamberu/ (lit. 'child' + 'daughter') = 'wife-takers' (Manik 1977)

20 Needham (1980) writes Veveva and Mamboru for Waijewa and Memboro in Fischer (1957) and the older Dutch sources. His map of the Sumbanese principalities (p.23) shows the centre of the Veveva and Mamboru domains to be only some $30 \mathrm{~km}$. apart, while their borders, separated by the tiny principality of Tana Rivu, come to within 3 or $4 \mathrm{~km}$. of one another. 
(3) MANGGARAI (west Flores): /anak rona/ (lit. 'child' + 'male') = 'wife-givers'; /anak wina/ (lit. 'child' + 'female') = 'wife-takers' (Gordon 1980)

(4) ATONI (west Timor): /an mone/ (lit. 'child' + 'male') = 'wife-givers'; /an feto/ (lit. 'child' + 'female') = 'wife-takers' (Cunningham 1964)

(5) TETUN (central Timor): /umah manéh/ (lit. 'house' + 'male') = 'wife-givers'; /fettoh sawa/ (lit. 'girdle' + 'female') = 'wife-takers' (van Wouden 1968:14)

(6) HUAULU (north coast of Seram): /hahamanal (lit. 'veranda' + 'male') = 'wifegivers'; /hahapina/ (lit. 'veranda' + 'female') = 'wife-takers' (Valeri 1980)

Surely this correspondence of morphologically transparent terminology for affinal groups involved in asymmetric alliance and of morphologically opaque terminology for crosssiblings cannot be accidental. But if not, what is its significance for the problem at hand?

Basically three alternatives are available: (1) treat the resemblance as coincidental, (2) assume that cross-sibling terms with the semantic structure 'male/female' or 'child' plus 'male/female' were historically transferred to the affinal groups in some societies that practiced asymmetric alliance, or (3) assume that terms with the semantic structure 'male/female' or 'child' + 'male/female' which designated the affinal groups in systems of asymmetric alliance came to apply instead to the cross-siblings.

Alternative (1) would provide no satisfactory explanation for what is clearly a greaterthan-chance similarity between terms that refer to the most pivotal relationships in systems of matrilateral cousin marriage, the first on the level of the individual, the second on the level of the social group. ${ }^{21}$

Alternative (2) again raises two questions: (1) why there are multiple PMP terms for the cross-siblings, when no daughter language has more than one term for either relationship, and (2) why terms would be innovated in meanings for which they are semantically unmotivated ('child' + 'male/female' for the cross-siblings) and then transferred to meanings for which they are semantically motivated.

Alternative (3) avoids both the problem of synonymy and the problem of morphological opacity. Apart from these negative advantages alternative (3) is also positively motivated. Reference to Table 1 shows that in dual symbolic classifications generally wife-givers are conceptually aligned with 'male' and 'superior', while wife-takers are conceptually aligned with 'female' and 'inferior'. As the sources clearly indicate, 'male' and 'female' in such classificatory schemas are to be understood as symbolic categories, not as sexual references. The wife-givers are thus 'male' even though they are the givers of women, and thus belong to the lineage of the wife. For the terminology relating to affinal groups to be applied to the cross-siblings, however, we must assume a transfer of group viewpoint from the individual participants in a marriage to their brother-sister parents. But how could such a transfer of viewpoint come about?

Fortunately, we need not resort to speculation about the native participant viewpoint in order to answer this question and thereby solve a major problem in understanding the history of sibling terminology in Austronesian languages. The answer rather is provided in the

21 Robin Fox (1967:236) regards "the fate of the brother-sister bond as in some ways 'central' to the elaboration of kinship systems". The evidence for the cross-sibling substitution drifts in Austronesian languages supports this statement entirely, at least in so far as it applies to systems of asymmetric alliance. 
careful ethnographic work that has been done on CMP-speaking societies in recent years. Regarding the terms for wif e-giving and wife-taking groups among the Huaulu of Seram, Valeri (1980:185) has the following to say:

Literally, "hahamana" means "male veranda"; "hahapina", "female veranda". "Veranda" here is a synecdoche for "house" (luma): it symbolises the social group associated with the luma in its relationship to another group, since the veranda is the part of the house reserved for social encounters. Like most peoples in central Seram, the Huaulu connote this opposition by the categorical opposition between "children of the brother (that is, hahamana)" and "children of the sister (hahapina)." This is quite logical, since otherwise the symbolic identification of the wife-givers with the male side would be absurd: if the hahamana/hahapina relationship were conceptualised, not in terms of the brother/sister relationship, but in terms of the affinal relationship between wife and husband, the wife-givers side would be female, not male. As a matter of fact, the point of view is that of a brother: the male sibling stays with his paternal lineage, the female sibling is given away; male children stay with their father, female children are married out. Not surprisingly, "hahamana" is also glossed "male child" and "hahapina" "female child." It is evident that in native conceptualisation the wife-giving/wife-taking relationship is subsumed under more fundamental relationships: children of the brother/children of the sister, brother/sister, and finally, male/female.

This quotation from Valeri could hardly be clearer or more appropriate to our purpose. If the 'extra' set of cross-sibling terms that we have discovered did not refer to cross-siblings in Proto Malayo-Polynesian (since ${ }^{*} b e t a w$ and ${ }^{*} \tilde{n} a R a$ had those meanings) they must have had some other meaning. The only other meaning that can be attributed to them is that of the affinal groups to which they refer in attested systems of asymmetric alliance. That this was the probable direction of semantic change (from 'WG' to ' $B$ (w.s.)' and from ' $W T$ ' to ' $Z$ (m.s.)') is made more likely by the alignment of wife-givers with 'male' and of wife-takers with 'female' in the dual symbolic classifications of these same societies. Those terms which reflect *anak plus a gender qualifier are glossed by Fox (1980c:333) as 'children of the brother' (= wife-givers) and 'children of the sister' (= wife-takers). They could as easily be glossed 'member of the male group' and 'member of the female group', since PMP *anak is widely reflected not only in the literal sense 'child', but also in the wider sense 'member of a (social, occupational, etc.) group'.22

22 In addition to the names of wife-givers and wife-takers noted at the beginning of this section, compare, for example, Malay anak kapal (= 'child' + 'ship') 'crewmember of a ship', Old Javanese anak wanwa (= 'child' + 'inhabited place') 'person belonging to the wanwa community', Erai anaili (= 'child' + 'village') 'villagers', and the non-cognate but structurally parallel Hawaiian kama?āina (= 'child' + 'land') 'native-born'. In view of this range of meanings Needham (pers.comm.) questions whether *anak should be glossed 'child', or should rather be given a more general gloss such as 'junior associate' or 'minor complement'. In effect he denies any special value to the meaning 'child' as opposed to other meanings with which it shares a category membership. The basic problem with his position is that it fails to explain why the category membership associated with reflexes of *anak may show considerable crosslinguistic variation, yet the category itself is invariably recognised by its inclusion of the meaning 'child'. With respect to the morphologically complex terms, Needham (1978:118) renders Karo Batak anak beru as 'people of the woman,' 'the woman's people,' or 'one's daughter's (or sister's) family.' I regard this as preferable to Fox's translation of cross-sibling terms of similar semantic structure in eastern Indonesia, since it recognises that anak is not to be translated literally as 'child'. However, both Fox ani Needham translate 'male' and 'female' as literal sexual references rather than as labels in a dual 
Before concluding it will be well for us to take stock of what the comparative study of sibling terms has enabled us to infer about the history of social change in Austronesianspeaking societies. Firstly, terms such as Kambera (eastern Sumba) /ana mini/ 'B (w.s.)', /ana wini/ ' $Z$ (m.s.)' and Memboro (north-west Sumba) /ana moni/ 'B (w.s.)', /ana wini/ ' $Z$ (m.s.)' reflect PMP expressions which almost certainly did not refer to the cross-siblings, but rather to the wife-giving and wife-taking groups in a system of asymmetric alliance. When they came to be applied instead to the cross-siblings, they replaced the reflexes of PMP * ñaRa and *betaw which are still retained in such closely related languages as that of Waijewa (west Sumba), which has /na?a/ 'B (w.s.)' and /woto/ 'Z (m.s.)'.

Many social anthropologists and ethnologists with an interest in comparative questions will no doubt be willing to grant this much. But how without a serious breach of method can we stop here? If the societies of eastern Sumba and Savu have acquired new cross-sibling terms from the terms for affinal groups how are we to explain the parallel terminological innovations in various languages of the northern and southern Philippines, in Malagasy, in Middle Malay, in Sangir, in southern Toraja (Tae') and other languages of Sulawesi, and in Proto Oceanic, the ancestor of some 450 modern Austronesian languages? Unlike the situation among CMP-speaking groups, where MBD marriage is common, none of these societies have had systems of asymmetric alliance within the ethnographic present. How can the innovative terms for cross-siblings be explained from earlier terms for wife-givers and wife-takers if wife-giving and wife-taking corporate groups do not now exist in these societies?

Linguists will not find the general form of this question difficult, since some of the classical discoveries in Indo-European linguistics involved the use of observations about one language to explain observations in another. Grimm's Law, as it was initially formulated, contained many apparent exceptions. Verner's Law explained a large number of these as regular developments by demonstrating that the Germanic languages had retained Proto IndoEuropean contrastive accent at the time of the First Germanic Consonant Shift. Yet no attested Germanic language (including the extinct Gothic, and Old Norse, for which historical texts are available) retains the original accent pattern, which was inferred largely from agreements between Sanskrit and Greek. What the Germanic languages show is rather the traces of an earlier accent system as it affected the development of adjacent consonants perhaps 2,500 years ago. To echo the form of the question at the conclusion of the preceding paragraph, we might equally well ask: How can Verner's Law explain any exception to Grimm's Law if the Proto Indo-European accent has not been preserved in any attested Germanic language?

Returning to the original question, there is no easy answer unless we propose that at the time of terminological transfer the societies in question practised asymmetric alliance. Without such a hypothesis there is no explanation for the appearance of an 'extra' set of cross-sibling terms without a corresponding 'extra' set of parallel sibling terms. Moreover, it is clear that the reflexes of PMP * $\tilde{n} a R a$ and *betaw were replaced independently in such CMP languages as Kambera or Memboro of Sumba and in such WMP languages as Bontok, Malagasy or Tae'. In other words, the historical shift of reference from wife-giving and wife-taking group to the cross-siblings was a drift - a change that took place independently

symbolic classification (see Table 1). Under this interpretation a usage such as Dairi-Pakpak Batak anak hamberu (lit. 'child' + 'daughter' [= Karo Batak beru 'female']) 'address of a woman to her husband' is unintelligible, yet the personal dyads B-Z, W-H, BD-FZ and MB-ZS can each be seen as manifesting the opposition of wife-giving and wife-taking lineages. 
and recurrently in a number of societies over the millenia as the Austronesian-speaking peoples separated and diversified from a common ancestral community. These changes, which we can call the 'cross-sibling substitution drifts', show unmistakeably that the motor of linguistic drift need not be limited to the persistent operation of inherited structural pressures in language. Rather, linguistic drift can be also be powered by the persistent operation of inherited structural pressures in social organisation.

\section{OBJECTIONS AND ALTERNATIVES}

At the very least, anyone who wishes to object to the foregoing proposals must provide alternative answers to the following questions: (1) Why, next to reflexes of PMP * $\tilde{n} a R a$ and *betaw, do we find reflexes of an 'extra' set of cross-sibling terms in a number of WMP, CMP and OC languages when: (a) only one set of reflexes is found for the parallel sibling terms, and (b) no attested language has more than one set of terms for the cross-siblings?; (2) Why is this extra set of terms semantically derivative (primary sense = 'male/female') or morphologically complex (primary sense $=$ 'child/member of social group' + 'male/female'), while * ñaRa and *betaw are semantically primary and morphologically simple?; (3) Why would this extra set of terms evolve independently in a number of widely scattered languages?; and (4) Why are terms of parallel semantic structure ('child/member of a social group' + 'male/female') found in the meanings 'wife-giver' and 'wife-taker' both in WMP and in CMP languages? Needless to say, any set of alternative answers to these questions should form part of a coherent theory of the evolution of social organisation in the Austronesian-speaking world.

One objection that is likely to be raised against the claim that PMP society practised asymmetric alliance comes from what might be called the 'internal logic' of kinship systems. In any society with exclusive matrilateral cross-cousin marriage certain terminological equations are to be expected (e.g. $\mathrm{MB}=\mathrm{WF}, \mathrm{MBS}=\mathrm{WB}$ ), while others are not (e.g. $\mathrm{MB}=\mathrm{HF}$, $\mathrm{MB}=\mathrm{FZH}$ ). This is not the place for me to attempt a reconstruction of the entire set of PMP kinship terms; indeed, the force of my argument requires no reconstructed terminology beyond the sibling terms themselves. Nonetheless, given the probability that terminological incompatibilities will present an issue it might be worthwhile to briefly consider one additional cognate set which was the subject of some debate in reactions to Blust (1980b).

Blust (1980b:213) reconstructed PMP *ma(n)tuqa (now written *ma-tuqah) with the meanings 'MB', 'WF', adding in a footnote 'Possibly also WM, HF, HM'. Aberle (1980:228) correctly pointed out that the evidence cited in Blust (1980b) actually supports an association of PMP *ma-tuqah with all four affinal meanings, as well as 'MB'. He then added "Yet in a system of prescriptive alliance one expects only the equation of MB and WF, if the terminology reflects MBD marriage. If, on the other hand, MB is equated with WF and HF the result is compatible with symmetric rather than asymmetric exchange, while the equation of MB and spouse's mother is anomalous under either hypothesis".

It is important to recognise that application of the Dyen/Aberle procedures simply maps a reconstructed morpheme ('candidate') onto those universal kin categories which are associated with its 'unincluded' reflexes. The result may be a concatenation of kin categories which is unlikely to form a genealogical category in any natural language. When such a result is obtained from mechanical application of the procedures it must be subjected to further analysis. In the case at hand reflexes of PMP *ma-tuqah are associated with 'MB' in WMP, 
CMP and OC languages, and with 'WF', 'WM', 'HF', 'HM' in WMP and CMP languages. Given the subgrouping which I adopt (section 3.3), it follows mechanically that *ma-tuqah must be glossed 'MB', 'WF', 'WM', 'HF', 'HM'. Needless to say, such a concatenation of categories is the product of comparing of ten incomplete sources, and may contain both too little and too much. Indeed, it is clear that the substring ' $M B=W F=W M$ ' logically entails ' $\mathrm{MBW}$ ', and so expands to ' $\mathrm{MB}=\mathrm{WF}=\mathrm{MBW}=\mathrm{WM}$ '.

Even without the foregoing caveat, closer attention to the material in Blust (1980b:213, Table 4) shows that next to the meanings that Aberle associates with PMP *ma-tuqah we must also associate the more restricted set of glosses 'MB', 'WF', 'WM', since matua in Nias (WMP) and tu?a in some dialects of Manggarai (CMP) mean 'WF', 'WM', but do not refer to the parents-in-law of a woman. Although Dyen and Aberle (1974) treat the role of inclusion in lexical reconstruction at some length, I find no discussion of how they treat two unincluded candidates when one of these is semantically a subset of the other (as *ma-tuqah ' $\mathrm{MB}=\mathrm{WF}=\mathrm{MBW}=\mathrm{WM}$ ' is to ${ }^{*}$ ma-tuqah ' $\mathrm{MB}=\mathrm{WF}=\mathrm{MBW}=\mathrm{WM}=\mathrm{FZH}=\mathrm{HF}=\mathrm{FZ}=\mathrm{HM}$ '). The only guiding principle which they make explicit (p.18) is that "an unincluded candidate is inferred to have had...the meaning of the list in which it is found". In accordance with this principle the Dyen-Aberle method requires not the reconstruction PMP *ma-tuqah ' $\mathrm{MB}=\mathrm{WF}=\mathrm{MBW}=\mathrm{WM}=\mathrm{FZH}=\mathrm{HF}=\mathrm{FZ}=\mathrm{HM}$ ', but both this meaning and 'MB=WF=MBW=WM'.

Although he subsequently dismisses not only my conclusions, but also his own on the grounds that "the subgrouping is not justified" (1980:230), Aberle's inference of symmetric alliance can in any case be justified only in part, since the evidence from PMP *ma-tuqah actually is contradictory, supporting both an inference of symmetric alliance and an inference of asymmetric alliance. ${ }^{23}$

Aberle's objections raise two interrelated questions: (1) Do kinship terminology and behaviour always reflect one another? (2) If not, can comparative linguistics resolve any issues in the reconstruction of prehistoric social organisation? Needham $(1967,1984)$ has argued for an evolution from symmetric to asymmetric terminology in the societies of the Lesser Sunda Islands of eastern Indonesia. His principle argument is that the "transformation" of a symmetric to an asymmetric system is inherently unlikely because (1984:229):

...the normal development of social forms is in the direction of increasing intricacy. For an asymmetric system to change into a symmetric system would involve a reduction in the number of terms, and a reduction in the number of lines from three to two. This is a transformation in the direction of economy of means and simplicity of structure; it is not formally self-contradictory or otherwise invalid, but it is empirically improbable. It would mean the abolition of terminological distinctions, in the medial three genealogical levels at least, in

23 Dyen $(1985: 365,388)$ similarly objects to the reconstruction of PMP *ma-tuqah 'MB/WF', but on different grounds, claiming (p.365) that "Each meaning is found in a separate branch of PMP: the first in Proto Oceanic (PO) and the second in Proto Western Malayo-Polynesian". Entirely apart from our disagreement over the methodological issues associated with what he calls "single witness" comparisons (called "no candidate" comparisons in Blust 1987a), Dyen's statement can only be made by ignoring the WMP reflexes of *ma-tuqah which are associated with the meaning 'MB' (Blust 1980b, Table 4), and the considerable evidence for a Central-Eastern Malayo-Polynesian subgroup (Blust 1974a, 1983-1984b, 1993). 
favour of equivalences. This is an operation of which, so far as I can discover, there are no well-attested ethnographic instances.

Needham's claim regarding the development of social forms "in the direction of increasing intricacy" expresses an implicit theory of unilinear evolution. In this sense his views are not unlike those of Brown (1984), who maintains that the evolution of terminological systems in language is towards an ever increasing number of general category distinctions, correlated with an ever increasing scale of societal complexity. Just as Brown's evolutionary arguments are dubious (Blust 1985), so are Needham's. In fact, Needham provides no concrete evidence for his assertion, maintaining simply that its converse "is empirically improbable".24

Although he offers no developed argument in support of his claim, Needham's "normal development of social forms" makes an explicit linguistic prediction: the change from symmetric to asymmetric terminologies requires terminological innovations to fill the increasing number of distinctions that must be recognised in a (minimally) three-line system arising from an earlier two-line system. In particular, the equivalences $F Z=W M$, and $\mathrm{FZH}=\mathrm{WF}$ in a two-line system become non-equivalences in a three-line system, creating a need for new terms in the meanings FZ and FZH. I am aware of four cognate sets on the PMP level which evidently referred to kin of the parental generation. The reconstructions to which these can be assigned are: (1) *ina, (2) *ama, (3) *ma-tuqah, and (4) *aya. Table 5 sets out the glosses which I propose for these terms:

TABLE 5: PMP CONSANGUINEAL AND AFFINAL TERMINOLOGY FOR THE PARENTAL GENERATION

Term
*ina
*ama
*ma-tuqah
*aya

Meanings

$\mathrm{M}, \mathrm{MZ}, \mathrm{FBW}$

$\mathrm{F}, \mathrm{FB}, \mathrm{MZH}$

MB, MBW, (WF), (WM)

FZ, FZH, (HF), (HM)

The glosses assigned to PMP *ina and *ama require little justification, as they are almost universally supported in Austronesian languages. As noted in Blust (1980b), both *ma-tuqah and *aya clearly referred to relatives of the parental generation. The former is widely reflected in Oceanic languages in the meaning 'MB', and was reconstructed for Proto Oceanic in this meaning by Milke (1958). Similar meanings appear in some CMP languages, as with Manggarai /tu?a ata rona/ 'MB' and Fordat /dua/ 'owner, sir, master; MB (in so far as he is empowered to oversee his $\mathrm{ZC)}$ ', and a wider avuncular reference appears in such WMP lariguages as Mukah (Sarawak) /tua?/ 'FB, MB, FZH, MZH'. On the other hand, *ma-tuqah is reflected in the meaning 'WF, WM, HF, HM' both in WMP and in CMP languages. In attempting to reconcile these glosses with a single reconstructed morpheme a conflict arises. The gloss ' $\mathrm{MB}, \mathrm{MBW}, \mathrm{WF}, \mathrm{WM}, \mathrm{HF}, \mathrm{HM}$ ' is consistent neither with asymmetric nor with symmetric exchange, since the former would exclude ' $\mathrm{HF}, \mathrm{HM}$ ' (hence: ' $M B, M B W, W F, W M '$ ') and the latter would include 'FZ, FZH' (hence: 'MB,

24 Allen (1989) proposes a more general model of semantic evolution which predicts that symmetric terminolgies must precede asymmetric terminologies. His concern is with the evolution of kinship terminologies throughout the span of human history rather than with the more recent evolution of kinship terminologies within the context of particular language families. Although claims about longer evolutionary trends presumably would hold true for shorter evolutionary trends as well (since in his model the course of change is unidirectional), he does not directly address any set of real data. 
MBW, WF, WM, HF, HM, FZ, FZH'). But it is evident that we must also reconstruct PMP * aya as a kin term of the parental generation, and this contributes to a resolution of the meaning of *ma-tuqah. Unlike PMP *ma-tuqah, reflexes of *aya have no known affinal senses. As noted in Blust (1980b) this difference in semantic profile between reflexes of the two terms almost certainly is due to the dominance of male viewpoint in the historical evolution of kinship terms that make use of a parameter of relative sex. Although both *matuqah and *aya were affinal terms, the former meant 'parent-in-law' only to a male speaker, and the latter only to a female speaker. Most reflexes of *aya mean either 'mother' or 'father'. In this sense they are fundamentally different from reflexes of *ina (which is never reflected in the meaning 'father'), *ama (which is never reflected in the meaning 'mother'), and *ma-tuqah, which shows no traces of sexual polarity. Since a terminology of symmetric exchange requires only a single term for parental cross-siblings, their spouses, and the parents-in-law of Ego, Needham's hypothesis of a general evolution from symmetric to asymmetric terminologies clearly is inconsistent with the available linguistic evidence (some of which has been in print for over a decade). ${ }^{25}$

Despite this criticism Needham (1984) is a valuable contribution in a number of respects. In his paper Needham examines the terminologies of 15 societies in the Lesser Sunda Islands of eastern Indonesia. He finds that seven of these are consistently and unambiguously symmetric (2) or asymmetric (5), while the remaining eight are inconsistent, ambiguous or otherwise problematic. In all, eight of the 15 terminologies show some symmetric features. Despite these terminological differences all 15 societies practise (or traditionally practised) asymmetric alliance. Since changes in terminology are likely to lag behind changes in social organisation Needham sees in this inconsistency between terminology and behaviour further support for his inference of an evolution from symmetric to asymmetric terminologies, and by implication a parallel evolution from symmetric to asymmetric exchange.

But if terminology and behaviour do not reflect one another in half of the societies in Needham's sample, how can we be sure that they did in Proto Malayo-Polynesian? The conclusion to be drawn from Needham's data in conjunction with the cross-sibling substitution drifts is that asymmetric alliance as a system of social organisation is inferrable for PMP regardless of the terminological system that we reconstruct. Far from being a cause for discouragement, the lack of correspondence between terminology and behaviour in attested societies need not stand in the way of inferences about earlier forms of social organisation that are based on the study of cognate terminology. The power of the comparative method of linguistics is that inferences supported by it need not be restricted to 'horizontal' relationships within a reconstructed system, but include 'vertical' relationships

25 Despite our differences on several important points of method, Aberle (1980:229) agrees that PMP *aya probably meant ' $F Z$ '. The evidence necessary to reach this conclusion through the procedures which he regards as indispensable is contained in: (WMP) Western Bukidnon Manobo /aya-?/ 'MZ, FZ', Seru /aya/ 'MZ, FZ, MB, FB'; (CMP) Sika /?aa/ 'FZ', Moa /yei/ 'MB, FB'; (OC) Motu /lala/ 'FZ', Dobu /yaia-na/ 'all females of the first generation ascendant of father's village' (Fortune 1963[1932]:37). Even without these direct indications of a reference to the paternal aunt I believe the inference of PMP *aya 'FZ, FZH' would be forced by four considerations: (1) the term *aya must be reconstructed for PMP and assigned a gloss; (2) the gloss must refer to a relative of the parental generation; (3) this relative cannot have been either parent (since *ina meant 'mother' and *ama meant 'father', and reflexes of these terms invariably refer to the same parent without cross-over of sex); and (4) this relative cannot have been the maternal uncle, since *aya is never reflected in that meaning. Both by a process of elimination, and by attempting to come to terms with the fact that reflexes refer with almost equal frequency to a female and to a male relative, we are then left with no reasonable alternative to the conclusion that PMP *aya meant 'FZ, FZH'. 
arising from the comparison of heterosemantic cognates. If it was the case that speakers of Proto Malayo-Polynesian practised symmetric rather than asymmetric alliance we would have no theoretical basis for explaining the peculiar set of observations that I have labelled the 'cross-sibling substitution drifts', since these require the persistence over many generations of a system of marital alliance characterised by descent group hierarchy ('male/superior/wifegivers' vs 'female/inferior/wife-takers'). These remarkable linguistic developments would, in effect, become a drift without a motive force, a collection of surprising parallel changes that have no statable cause.

Finally, the objection may be raised that I propose no concrete steps to show how a system of asymmetric alliance could evolve into any of the other types of social organisation which are found among Austronesian-speaking peoples today. As a linguist I make no claims to expertise in kinship theory. While I am able to propose a dynamic of terminological change, I do not feel that it is my place to propose a dynamic of social change; this is, after all, the domain of the social anthropologist. In a similar vein, Forth (1990) engages in linguistic comparison, but excuses himself from proposing reconstructions (and hence explicitly accounting for sound correspondences) on the grounds that he is not a linguist. In attempting the reconstruction of linguistic forms and their meanings all that I feel obligated to address is the reconstructed baseline to which an evolutionary hypothesis might apply. As with an earlier proposal which reconstructed matrilineal descent as the predecessor of the presently patrilineal societies of the south-eastern Solomon Islands (Blust 1986-87), I leave it to the social anthropologist to work out the mechanisms through which the reconstructed system evolved into its descendant forms.

\section{APPENDIX}

Because the sibling terminologies discussed in the body of this paper are displayed in cognate sets, they do not appear as integral wholes. To facilitate easy reference this appendix presents the full sets of sibling terms for all languages mentioned in the text which make use of a parameter of relative sex. This serves to show at a glance that Murdock (1968) not only underestimated the extent to which relative sex terminologies occur in the Philippines and western Indonesia, but also failed to recognise that similar systems must be reconstructed for Proto Philippines (*laki 'B (w.s.)', *ba-bahi 'Z (m.s.)'), and for Proto Malayo-Polynesian ( ${ }^{*} \tilde{a} \mathrm{Ra}$ 'B (w.s.)', *betaw ' $\mathrm{Z}$ (m.s.)'). For reasons of space (and because little would be gained from doing so) I do not consider the extension of these terms to collateral relatives.

The type of sibling terminology that I attribute to Proto Malayo-Polynesian corresponds to Type 12 in Nerlove and Romney (1967), with the proviso that the elder/younger terms may have applied to cross-siblings as well as to parallel siblings. Although Murdock (1968:7) reportedly consulted sources for 104 societies which speak "Malayo-Polynesian" languages, it is noteworthy that he does not mention this structure at all among the four varieties that he subsumes under his Type F, the "Melanesian, or Relative Sex Type". There are two explanations for this curious oversight. Firstly, as he himself notes (1968:1), his coverage of eastern Indonesia is inadequate. More seriously, however, Murdock overlooked the existence of a relative sex parameter in the sibling terminology of a number of WMPspeaking societies because (like most social anthropologists) he failed to use available linguistic sources, as opposed to ethnographic sources. The possible excuse that linguistic sources are likely to be less accurate than ethnographic sources in glossing kinship terminology simply does not bear close scrutiny. Among linguistic sources that provide 
explicit evidence of a relative sex distinction in the sibling terminology of WMP languages are: (1) Reid (1976) for Bontok of northern Luzon, (2) McKaughan and Macaraya (1967) for Maranao, (3) Elkins (1968) for Western Bukidnon Manobo, (4) Schlegel (1971) for Tiruray, all of southern Mindanao, Philippines, (5) Hardeland (1859) for Ngaju Dayak of south-east Borneo, (6) Richardson (1885) for Malagasy, (7) Warneck (1977[1906]) for Toba Batak of northern Sumatra, (8) Helfrich (1904) for Middle Malay of eastern Sumatra, (9) Steller and Aebersold (1959) for Sangir of northern Sulawesi, (10) Dunnebier (1951) for Bolaang Mongondow of north-central Sulawesi, and (11) van der Veen (1940) for southern Toraja of central Sulawesi. Although some of these sources were not available when Murdock published his study, more than half of them were. As Fox (1988b:38) has pointed out, Kroeber's (1919) reconstruction of the "ancient Philippine" kinship system probably contains some critical lacunae, including "terms for male and female in Ego's generation". Fox could have determined this for himself by checking the relevant dictionaries. The task is now made easier by the publication of Elkins and Hendrickson (EH) (1984), although this publication does not include data on Bontok or Ilongot.

\begin{tabular}{|c|c|c|c|}
\hline $\begin{array}{l}\text { BONTOK } \\
\text { (Reid 1976) }\end{array}$ & & $\begin{array}{l}\text { ILONGOT } \\
\text { (Rosaldo }\end{array}$ & 1975) \\
\hline etad & $\mathrm{Sb}$ & katan?agi & $\mathrm{Sb}$ \\
\hline iyon?a & $\mathrm{eB}$ & eka & $\mathrm{eSb}(=\mathrm{e} / / ?)$ \\
\hline naodi & yB & agi & $\mathrm{ySb}(=\mathrm{y} / / ?)$ \\
\hline ka-lalaki-an & $\mathrm{xm}$ & raki & $\mathrm{xm}$ \\
\hline ka-babai-an & $x f$ & be:kur & $x f$ \\
\hline $\begin{array}{l}\text { MANOBO, } \\
\text { (EH 1984) }\end{array}$ & KIDNON & $\begin{array}{l}\text { MANOBC } \\
\text { (EH 1984) }\end{array}$ & \\
\hline suled & /l & kako-y & e/l \\
\hline me?emahan & $\mathrm{xm}$ & hari & $\mathrm{y} / /$ \\
\hline etevey & $x f$ & ma?ama & $\mathrm{xm}$ \\
\hline (variants: sys & anging) & ataboy & $x f$ \\
\hline $\begin{array}{l}\text { BINUKID } \\
\text { (EH 1984) }\end{array}$ & & $\begin{array}{l}\text { KALAGA } \\
\text { (EH 1984) }\end{array}$ & KAULU \\
\hline suled & // & magulaj & e/l \\
\hline ma?ama & $\mathrm{xm}$ & majud & $y / l$ \\
\hline atebay & $x f$ & inulug & $\mathrm{xm}$ \\
\hline & & bubay & $x f$ \\
\hline $\begin{array}{l}\text { MANOBO, C } \\
\text { (EH 1984) }\end{array}$ & ATO & $\begin{array}{l}\text { MANOBC } \\
\text { (EH 1984) }\end{array}$ & AWON \\
\hline kaka-y & ell & su?un & $/ /$ \\
\hline hadi & $y / l$ & ma?ama & $\mathrm{xm}$ \\
\hline ma?ama & $\mathrm{xm}$ & atoboy & $x f$ \\
\hline tebay & $x f$ & & \\
\hline $\begin{array}{l}\text { TBOLI } \\
\text { (EH 1984) }\end{array}$ & & $\begin{array}{l}\text { TIRURAY } \\
\text { (Schlegel }\end{array}$ & \\
\hline twogu & ell & ofo? & $\mathrm{eSb}$ \\
\hline twoli & $y / /$ & tuwarey & $\mathrm{ySb}$ \\
\hline $\log i$ & $\mathrm{xm}$ & lagey & $\mathrm{xm}$ \\
\hline libun & $x f$ & libun & $x f$ \\
\hline
\end{tabular}


MARANAO

(McKaughan \& Macaraya 1967)

$\begin{array}{ll}\text { pagari/panaman } & \mathrm{Sb} \\ \text { kaka } & \mathrm{e}(=\mathrm{e} / / ?) \\ \text { ari } & \mathrm{y}(=\mathrm{y} / / ?) \\ \text { laki } & \mathrm{xm} \\ \text { babai } & \mathrm{Z}(=\mathrm{xf})\end{array}$

NGAJU DAYAK

(Hardeland 1859)

$\begin{array}{ll}\text { aka/kaka } & \text { eSb } \\ \text { andi } & \text { ySb } \\ \text { pahari } & \text { // } \\ \text { ñahE } & \text { xm } \\ \text { betaw } & \text { xf }\end{array}$

KARO BATAK

(Singarimbun 1975)

kaka

$\mathrm{eSb}$

agi

senina

turaj

WG: kalimbubu ${ }^{26}$

WT: anak beru

TOBA BATAK

(Vergouwen 1964, Warneck 1977)

haha

angi

ell

i-boto

y/l

WG: hula-hula

$\mathrm{x}$

WT: boru

REJANG

(Lebar 1972a)

kako-?

asua?

guaneui

klaweui

$\mathrm{eSb}(=\mathrm{e} / / ?)$

$\mathrm{ySb}(=\mathrm{y} / / ?)$

$\mathrm{xm}$

$\mathrm{xf}$

\section{BOLAANG MONGONDOW}

(Dunnebier 1951)

utat

$\mathrm{Sb}$

guyan guyan

ai ai y

lolaki

bobai

$\mathrm{eSb}(=\mathrm{e} / / ?)$

$\mathrm{Sb}(=\mathrm{y} / / ?)$

$\mathrm{xm}$

$\mathrm{Z}(=\mathrm{xf})$
BERAWAN, LONG TERAWAN

(Proctor 1979, Blust n.d.b)

padi?

$\mathrm{Sb}$

tukeh

$\mathrm{eSb}(=\mathrm{e} / / ?)$

taréh

$\mathrm{ySb}(=\mathrm{y} / / ?)$

betaw

$\mathrm{Z}$ (=xf?)

MALAGASY

(Richardson 1885)

rahalahy

$\mathrm{I} / \mathrm{m}$

rahavavy

//f

anadahy

xm

anabavy

$\mathrm{xf}$

\section{DAIRI-PAKPAK BATAK}

(Manik 1977)

kaka

ell

ajgi

y/l

turay

$\mathrm{x}$

WG: kula kula

WT: anak hamberu

MIDDLE MALAY

(Helf rich 1904)

kaka-?

adi-n

moanay

kelaway

$\mathrm{eSb}(=\mathrm{e} / /$ ?)

$\mathrm{ySb}(=\mathrm{y} / /)$

xm

$\mathrm{xf}$

SANGIR

(Steller \& Aebersold 1959)

turan

eSb (ref.)

aka- $\bigcap$ kaka-? e// (addr.)

tuari

$\mathrm{ySb}(=\mathrm{y} / /)$

mahuane

bawine

$\mathrm{B}(=\mathrm{xm})$

$\mathrm{xf}$

TAE'

(van der Veen 1940)

kaka-(?)

$\mathrm{eSb}(=\mathrm{e} / / ?)$

adi

anakmuane

$\mathrm{ySb}(=\mathrm{y} / /$ ?)

anak dara

$x f$ 
KOMODO

(Verheijen 1982)

(ha)ha

ari

na

ncawa

WG: (?)

WT: (?)

NGADHA

(Amdt 1961)

$k a e$

azi

nara

veta

WG: (?)

WT: (?)

SIKA

(Meyer 1937)

nara

wine

WG: (?)

WT: (?)

WAUJEWA

(Fischer 1957)

anu wua

aju mawine

na?a

woto

WG: (?)

WT: (?)

\section{MEMBORO}

(Fischer 1957)

a ju wua

anu kawini

anamoni

ana wini

WG: yera

WT: layia
MANGGARAI

(Verheijen 1970)

ka?e ell

ase $\mathrm{y} / \mathrm{l}$

nara $\quad \mathrm{xm}$

weta $\quad \mathrm{xf}$

WG: anak rona

WT: anak wina

ENDEH

(Needham 1968, 1970)

$\mathrm{ka}$ ?

el/

ari

y/l

nara

$\mathrm{xm}$

veta

$\mathrm{xf}$

WG: éja

WT: éja

SOLORESE

(Barnes 1972)

$\mathrm{Zm}$ (=xf)

kaka

$\mathrm{eSb}(=\mathrm{e} / /$ ?)

ari-n

naa

$\mathrm{ySb}(=\mathrm{y} / /$ ?)

bine

$\mathrm{xm}$

$\mathrm{xf}$

WG: (?)

WT: (?)

KAMBERA

(Forth 1981, Onvlee 1984)

apu paluhu

$/ / \mathrm{m}$

anu kawini

I/f

eri

anamini

$\mathrm{ySb}(=\mathrm{y} / / ?)$

$\mathrm{xf}$

ana wini

$\mathrm{xm}$

$\mathrm{xf}$

WG: yera

WT: layia/anakawini

ROTI

(Fox, pers.comm.)

$\mathrm{ka}^{\text {?a }}$

ell

fadi

yll

na

$\mathrm{xm}$

feto

xf

WG: (?)

WT: (?) 
SAVU

(Wijngaarden 1896)

a?a

ari

na mone

na weni

WG: (?)

WT: (?)

TETUN

(Morris 1984)

mau-n

bii-n

ali-n

naa- $n$

feto-n

WG: (?)

WT: (?)

WETAN

(de Josselin de Jong 1987)

jali

riwa

kaka

nara

WG: (?)

WT: (?)

ALUNE

(Sierevelt 1920)

béta

kwali

WG: (?)

WT: (?)

$\mathrm{I} / \mathrm{m}$

$\mathrm{ySb}(=\mathrm{y} / / ?)$

$\mathrm{eSb}(=\mathrm{e} / / ?)$

$\mathbf{x}$

em

ef

$\mathrm{ySb}(=\mathrm{y} / /)$

$\mathrm{xm}$

$\mathrm{Z}$ (=xf)
ATONI

(Schulte-Nordholt 1971)

tata- $f$

ell

oli-f

nau- $f$

fefo- $f$

$\mathrm{y} / /$

$\mathrm{xm}$

$x f$

WG: an mone

WT: an feto

LETI

(Jonker 1932)

ali

$\mathrm{m} / \mathrm{l}$

ela

nara

WG: (?)

WT: (?) f/l

$\mathrm{x}$
FORDAT

(Drabbe 1932a)

a?a

e/l

wari

WG: (?)

WT: (?)

\section{PAULOHI}

(Stresemann 1918)

wa?a eB

wari yB

leu manawa $\quad \mathrm{B}$

leupipina $\quad \mathrm{Z}$

WG: (?)

WT: (?)

SOBOYO

(Fortgens 1921)

$\begin{array}{ll}\text { kaka } & \mathrm{eSb}(=\mathrm{e} / / ?) \\ \text { uli? } & \mathrm{ySb}(=\mathrm{y} / / ?) \\ \text { naha } & \mathrm{xm} \\ \text { foto } & \mathrm{xf}\end{array}$

